\title{
HDAC7 Ubiquitination by the E3 Ligase CBX4 Is Involved in Contextual Fear Conditioning Memory Formation
}

\author{
ĐXu Jing, ${ }^{1 \star}$ Wen-Hai Sui, ${ }^{2 \star}$ Shuai Wang, ${ }^{1}$ Xu-Feng Xu, ${ }^{1}$ Rong-rong Yuan, ${ }^{1}$ Xiao-Rong Chen, ${ }^{1}$ Hui-Xian Ma, ${ }^{1}$ \\ Ying-Xiao Zhu, ${ }^{1}$ Jin-Kai Sun, ${ }^{1}$ Fan Yi, ${ }^{3}$ Zhe-Yu Chen, ${ }^{1}$ and Yue Wang ${ }^{1}$ \\ ${ }^{1}$ Department of Neurobiology, Shandong Provincial Key Laboratory of Mental Disorders, School of Medicine, Shandong University, Jinan, Shandong, \\ People's Republic of China, ${ }^{2}$ The Key Laboratory of Cardiovascular Remodeling and Function Research, Chinese Ministry of Education and Chinese \\ Ministry of Public Health, Qilu Hospital, Shandong University, Jinan, Shandong, People's Republic of China, and ${ }^{3}$ Department of Pharmacology, School of \\ Medicine, Shandong University, Jinan, Shandong, People's Republic of China
}

Histone acetylation, an epigenetic modification, plays an important role in long-term memory formation. Recently, histone deacetylase (HDAC) inhibitors were demonstrated to promote memory formation, which raises the intriguing possibility that they may be used to rescue memory deficits. However, additional research is necessary to clarify the roles of individual HDACs in memory. In this study, we demonstrated that HDAC7, within the dorsal hippocampus of C57BL6J mice, had a late and persistent decrease after contextual fear conditioning (CFC) training (4-24 h), which was involved in long-term CFC memory formation. We also showed that HDAC7 decreased via ubiquitin-dependent degradation. CBX4 was one of the HDAC7 E3 ligases involved in this process. Nur77, as one of the target genes of HDAC7, increased 6-24 h after CFC training and, accordingly, modulated the formation of CFC memory. Finally, HDAC7 was involved in the formation of other hippocampal-dependent memories, including the Morris water maze and object location test. The current findings facilitate an understanding of the molecular and cellular mechanisms of HDAC7 in the regulation of hippocampal-dependent memory.

Key words: CBX4; CFC; HDAC7; Nur77; ubiquitination

Significance Statement

The current findings demonstrated the effects of histone deacetylase 7 (HDAC7) on hippocampal-dependent memories. Moreover, we determined the mechanism of decreased HDAC7 in contextual fear conditioning (CFC) through ubiquitin-dependent protein degradation. We also verified that $\mathrm{CBX} 4$ was one of the HDAC7 E3 ligases. Finally, we demonstrated that Nur77, as one of the important targets for HDAC7, was involved in CFC memory formation. All of these proteins, including HDAC7, CBX4, and Nur77, could be potential therapeutic targets for preventing memory deficits in aging and neurological diseases.

\section{Introduction}

Specific genes that affect neuronal plasticity are crucial for long-term memory (Kandel et al., 2014). However, the molecules translated by these genes last only from several hours to several days, which may not maintain sufficient protein levels for long-term memory. In re-

\footnotetext{
Received Sept. 2, 2016; revised Feb. 24, 2017; accepted March 1, 2017.

Author contributions: X.J., W.-H.S., F.Y., Z.-Y.C., and Y.W. designed research; X.J., W.-H.S., S.W., X.-F.X., R.-r.Y., X.-R.C., H.-X.M., Y.-X.Z., and J.-K.S. performed research; X.J. and W.-H.S. contributed unpublished reagents/analytic tools; X.J., W.-H.S., and S.W. analyzed data; X.J., W.-H.S., and F.Y. wrote the paper.

This work was supported by the National Natural Science Foundation of China (Grants 31571100, 91432306, and 31401219), Shandong Province Natural Science Foundation (Grants ZR2014CM036 and ZR2014CQ023) and the Fundamental Research Funds of Shandong University.

The authors declare no competing financial interests.

${ }^{*}$ X.J. and W.-H.S. contributed equally to this work.

Correspondence should be addressed to Yue Wang, Department of Neurobiology, School of Medicine, Shandong University, No. 44 Wenhua Xi Road, Jinan, Shandong 250012, People's Republic of China. E-mail: wangyue@sdu.edu.cn.

DOI:10.1523/JNEUROSCI.2773-16.2017

Copyright $(\odot 2017$ the authors $\quad 0270-6474 / 17 / 373848-16 \$ 15.00 / 0$
}

cent studies, epigenetics has been demonstrated to be the basis for the sustained regulation of gene transcription (Woldemichael et al., 2014). Specifically, histone acetylation has been thoroughly investigated in many mental diseases in recent years. Acetylation may occur in specific sites in histones and is regulated by two classes of enzymes, including histone acetyltransferase (HAT) and histone deacetylase (HDAC) (Szyf, 2014). The deacetylation of histones is induced by HDACs to ensure that DNA is tightly associated with histones and chromatin is "closed" for transcription (Narlikar et al., 2002; Penney and Tsai, 2014).

It has been reported that the nonspecific inhibitors of HDACs may significantly improve the performance of animals in the contextual fear memory, object location, object recognition, and spatial memory tests (Zhao et al., 2010; Hawk et al., 2011; McQuown et al., 2011; Gräff et al., 2014), which is promising for the development of effective drugs to rescue memory deficits in multiple neurological disorders. However, the member diversity and the efficacy complexity of HDACs make this development not as easy as it appears. For 
example, knockout of HDAC3 promoted object location but not spatial memory. Moreover, knockout of HDAC5 damaged the spatial memory, but not the formation of fear memory in mice (Kim et al., 2012; Govindarajan et al., 2013). The overexpression of HDAC1 promoted the extinction, but not the formation of fear memory (Bahari-Javan et al., 2012). In contrast, the knockout of HDAC2 promoted the formation of fear memory (Guan et al., 2009). Therefore, additional research is necessary to clarify the roles of individual HDACs in learning and memory.

Using a microarray analysis, one study demonstrated that, $1 \mathrm{~h}$ after contextual fear conditioning (CFC), many HDACs changed in the hippocampus of adult male rats (Gupta-Agarwal et al., 2012). The HDAC1 and HDAC11 expression increased, whereas HDAC2, $H D A C 3, H D A C 5, H D A C 7$, and HDAC10 decreased. In that study, no direct functional experiments were conducted to verify the roles of these HDACs. Moreover, several HDACs performed contradictory functions with previous reports that the overexpression of HDAC1 promoted the extinction, but not the formation of fear memory (Bahari-Javan et al., 2012) and HDAC5 had no contribution to the formation of fear memory (Kim et al., 2012). Therefore, the roles of these candidate HDACs must be further clarified. HDAC7 is a member of the class II HDACs and has aroused substantial interest. The functions of HDAC7 have predominately been reported in the non-nervous system, such as the cardiovascular and immune systems (Dequiedt et al., 2005; Parra et al., 2007; Ha et al., 2008). HDAC7 expression in the hippocampus changed after CFC training (Gupta-Agarwal et al., 2012); however, there has been no direct evidence to date to indicate the functional roles of HDAC7 in CFC memory. Therefore, we performed a series of experiments to investigate the role and mechanism of HDAC7 in CFC memory. We determined that the HDAC7 protein level is selectively decreased in the dorsal hippocampus (DH) after CFC training. Overexpression or knock-down of HDAC7 in the DH effectively regulated the formation of CFC memory. The decrease in HDAC7 is caused by ubiquitin-related degradation and CBX4 and Nur77 are the E3 ligase and the target gene of $\mathrm{HDAC7}$ separately during $\mathrm{CFC}$ formation.

\section{Materials and Methods}

\section{Animals}

Male C57BL6J mice that weighed 23-25 g and were 8 weeks old were used. All mice were housed in a room at $22^{\circ} \mathrm{C} \pm 2{ }^{\circ} \mathrm{C}$ with a controlled light-dark cycle ( $12 \mathrm{~h}$ light/12 h dark), with food and water available ad libitum. All animal procedures were in accordance with the guidelines of the National Institutes of Health's Guide for the Care and Use of Laboratory Animals and were approved by the institutional animal care and use committee of Shandong University.

\section{Tissue isolation}

The tissue isolation was performed according to previous studies (Païzanis et al., 2010; O'Leary et al., 2012; Papatheodoropoulos, 2015; Luczynski et al., 2016). The DH of the mice was defined as AP: -0.94 to -2.30 $\mathrm{mm}$, the ventral hippocampus $(\mathrm{VH})$ was defined as AP: -2.46 to -3.80 $\mathrm{mm}$, and the amygdala (Amy) was defined as AP: -0.59 to $-2.45 \mathrm{~mm}$. The brains of the mice were removed and subsequently placed in a mouse brain slicer (Braintree Scientific). Coronal sections (1 mm thick) were collected and the previously described tissues were isolated following delineations from the mouse brain atlas under a dissecting microscope. The tissue was dissected on ice and stored at $-80^{\circ} \mathrm{C}$ until use.

\section{CFC}

The CFC experiment was performed according to previous studies (Huff et al., 2006; Lopez-Fernandez et al., 2007; Xu et al., 2015). The mice were placed in a standard fear conditioning chamber $(25 \times 25 \times 25 \mathrm{~cm})$ and allowed to habituate for $2 \mathrm{~min}$ without stimulation (habituation). Each mouse received 3 consecutive foot shocks ( $2 \mathrm{~s}$ duration each; weak, 0.4 $\mathrm{mA}$ or normal, $0.7 \mathrm{~mA}$ ) through a stainless steel grid floor (Panlab). Each foot shock was separated by a $58 \mathrm{~s}$ time period. After an additional $58 \mathrm{~s}$ after the last shock, the mice were returned to the home cages. The foot shock unconditioned stimulus (US) was generated by a programmable animal shocker and the conditioned stimulus (CS) comprised the experimental context. Short-term memory (STM) was tested at $1 \mathrm{~h}$ and longterm memory (LTM) was tested at $24 \mathrm{~h}$ after training. Two separate groups of mice were used for the STM and LTM tests. The mice were returned to the previous chamber in which the training occurred and were tested for 5 min without foot shock; memory was assessed by the duration of freezing behavior. In addition, to separate the impact of the "context" and the "shock" on the HDAC7 expression in the DH, two additional experiments were performed. To determine the effect of the context exposure ("context"), the mice were allowed to explore freely for $5 \mathrm{~min}$ in the training chamber without receiving a foot shock. To determine the effect of the shock and to minimize the context exposure ("immediate shock"), the mice were given a $2 \mathrm{~s}$ foot shock $(0.7 \mathrm{~mA})$ immediately after being placed in the training chamber and were quickly removed and returned to their home cages. Mice in the naive group were only housed in the standard home cage during CFC training.

\section{Object location test}

The experiment was performed according to a previous study (Vieira and Korzus, 2015). The mice were habituated in a testing apparatus for 10 min before training. The testing apparatus comprised an open field arena $(40 \times 40 \mathrm{~cm})$ with $35-\mathrm{cm}$-high walls. The floor was white with wallmounted visual cues (located on the north and east sides), which were visible in the arena. The behavior recording camera and the lamp were installed above. Two identical objects were placed in the NW and NE corners of the arena and the mice were allowed to explore these objects for $5 \mathrm{~min}$. Memory was subsequently assessed during a single, $5 \mathrm{~min}$ test trial after a $24 \mathrm{~h}$ delay (for LTM). During the test trial, replicas of the training objects were placed in a familiar (NW) corner and a novel (SE) corner. The times that the mice explored the object in the new and old positions were recorded independently.

\section{Morris water maze}

The Morris water maze test was performed according to our previous study (Yu et al., 2012). Briefly, the apparatus consisted of a circular water $\operatorname{tank}(120 \mathrm{~cm}$ diameter, $40 \mathrm{~cm}$ height $)$ filled with water $\left(22^{\circ} \mathrm{C}\right)$ to a depth of $25 \mathrm{~cm}$ and the water was made opaque by the addition of nontoxic white powder paint. A circular escape platform $(6 \mathrm{~cm}$ in diameter) was placed $1 \mathrm{~cm}$ below the water surface. A complete experiment consisted of a learning period (platform in place) with 4 trials per day for 5 consecutive days and a probe test (platform moved) on the sixth day. During the period of learning, the platform was always placed in the center of the same quadrant (target quadrant). Each trial consisted of a maximum of $60 \mathrm{~s}$ starting from one of the four quadrants with the animal facing the wall. If an animal did not reach the platform in $60 \mathrm{~s}$, it was guided to the platform. After reaching the platform, the mice were allowed to remain on it for $30 \mathrm{~s}$; they were then quickly dried with a towel and placed under a heating lamp set at exactly $37^{\circ} \mathrm{C}$ between each trial to avoid hypothermia. In the learning process, the escaped latencies for a single day were averaged to produce a daily mean. On the sixth day, the platform was removed, and the mice were allowed to swim for $60 \mathrm{~s}$. The number of platform crossings and the time spent in the four quadrants for each mouse were recorded with a video tracking system (Smart).

\section{Plasmid constructs and the viral information}

Mouse HDAC7 cDNA clone and adenovirus that expressing HDAC7 were purchased from Obio Technology. Adv-HDAC7 was tagged with Flag and EGFP successively in the C-terminal, with a P2A structure between Flag and EGFP. The Adv-con group expressed GFP. The HDAC7Flag construct used in HEK293 was subcloned into pCDNA3.1 with Flag tag in the C-terminal. HDAC7 S/A-Flag and HDAC7 S/D-Flag mutant constructs were subcloned with mutantion at 178,344 , and 479 aa sites from serine into alanine (S/A) or aspartic acid (S/D) separately. The target sequence for small hairpin RNA (shRNA) sh-HDAC7 was as follows: 5' GAC AAG AGC AAG CGA AGT G 3' (Mottet et al., 2007). The target sequence for sh-CBX4 was as follows: 5' CAG GGA AGA GCG GCA AGT ATT A 3'. The target sequence for sh-Nur77 was as follows: 
5' TCC CTG GCT TCA TTG AGC T 3 '. The target sequences for small hairpin control RNA (sh-con) of sh-HDAC7, sh-CBX4 and sh-Nur77 were scrambled. sh-HDAC7 used in HEK293 was subcloned in pSuperEGFP vector. Lentivirus that expressed sh-HDAC7 with a GFP tag was purchased from Obio Technology. All constructs created via PCR were confirmed by DNA sequencing (Genewiz) to exclude potential PCRintroduced mutations.

\section{Surgery and microinjection}

Before the surgery, the mice were anesthetized with $5 \%$ chloral hydrate $(0.8 \mathrm{ml} / 100$ g, i.p. $)$ and placed in a stereotaxic apparatus (8001; RWD Life Science). The mice were injected into the DH or Amy using a Hamilton microsyringe. The coordinates (in reference to bregma) were as follows: the DH: anteroposterior (AP), $-1.7 \mathrm{~mm}$; lateral (L), $\pm 1.5 \mathrm{~mm}$; dorsoventral (V), $-2.3 \mathrm{~mm}$ (Fortress et al., 2013); and basolateral Amy: AP, $-1.4 \mathrm{~mm} ; \mathrm{L}, \pm 3.5 \mathrm{~mm} ; \mathrm{V},-5.1 \mathrm{~mm}$ (Ogden et al., 2014). The infusions were performed in a volume of $1 \mu \mathrm{l}$ for $2 \mathrm{~min}$ and the infusion cannula was maintained for diffusion for an additional $4 \mathrm{~min}$. The mice were injected with lentivirus that expressed sh-HDAC7 for 4 weeks or HDAC7 adenovirus for 1 week.

\section{Cannula implantation}

Before the surgery, the mice were anesthetized with $5 \%$ chloral hydrate $(0.8 \mathrm{ml} / 100$ g, i.p.) and placed in a stereotaxic apparatus (8001; RWD Life Science). The mice were bilaterally implanted with 26-gauge guide cannulas to the DH. The coordinates (in reference to bregma) were as follows: the DH: anteroposterior (AP), $-1.7 \mathrm{~mm}$; lateral $(\mathrm{L}), \pm 1.5 \mathrm{~mm}$; dorsoventral (V), $-1.8 \mathrm{~mm}$ (Fortress et al., 2013). To prevent clogging, a stylus that was $0.5 \mathrm{~mm}$ longer was placed in the guide cannula. The guide cannulas were fixed by curing denture acrylic. After surgery, the animals were allowed to recover for 1 week before CFC training. The infusion cannula was connected to a $10 \mu \mathrm{l}$ microsyringe via PE20 tubing driven by a microinjection pump (KDS200; KD Scientific). $\beta$-Lactacystin ( $\beta$ Lac, $32 \mathrm{ng} / \mu \mathrm{l}, 0.5 \mu \mathrm{l} / \mathrm{side}$ ), cycloheximide (CHX, $200 \mu \mathrm{g} / \mu \mathrm{l}, 0.5 \mu \mathrm{l} / \mathrm{side}$ ), or vehicle were microinfused bilaterally $30 \mathrm{~min}$ before training.

\section{Immunofluorescence staining}

The mice were deeply anesthetized with $5 \%$ chloral hydrate $(0.8 \mathrm{ml} / 100$ g, i.p.) and transcardially perfused with $0.9 \% \mathrm{NaCl}$ solution, followed by $4 \%$ paraformaldehyde (PFA), $\mathrm{pH}$ 7.6. The brains were postfixed in $4 \%$ PFA overnight, followed by equilibration at $4^{\circ} \mathrm{C}$ in $30 \%$ sucrose before sectioning. The brains were frozen and sliced ( $40 \mu \mathrm{m}$, coronal) using a freezing microtome. The slices were blocked with a blocking solution (0.4\% Triton X-100 and 10\% normal donkey serum in TBS) for $1 \mathrm{~h}$ and incubated in the primary antibody for GFP (Thermo, A11122, 1:1000) overnight at $4{ }^{\circ} \mathrm{C}$. The slices were incubated with donkey anti-rabbit Alexa Fluor 488 (Thermo, A21206, 1:500) for $1 \mathrm{~h}$ at room temperature. The microphotographs were captured using confocal fluorescence microscopy with a Carl Zeiss LSM-780 microscope or a spinning disk microscope (Microstructural Platform of Shandong University). The images were analyzed using ImageJ.

\section{Immunohistochemistry (IHC)}

IHC staining was performed as described previously (Kim et al., 2013). The brains of CFC mice were collected at the indicated times. Naive mice were killed at the same time as the CFC 0 h group. Paraffin-embedded brain sections $(5 \mu \mathrm{m})$ from mice were deparaffinized in xylene and rehydrated through a graded ethanol series to water. Antigen retrieval was performed in $95^{\circ} \mathrm{C} 10 \mathrm{~mm}$ sodium citrate, $\mathrm{pH}$ 6.0, for $20 \mathrm{~min}$. Endogenous peroxidase activity for all sections was quenched with $3 \% \mathrm{H}_{2} \mathrm{O}_{2}$ while nonspecific binding was reduced with a blocking with buffer containing 10\% normal goat serum. The slides were stained for HDAC7 in sequential incubations with rabbit anti-HDAC7 antibody (Abcam, ab137366, 1:50) overnight at $4^{\circ} \mathrm{C}$, horseradish peroxidase-conjugated goat anti-rabbit IgG for $1 \mathrm{~h}$ at room temperature, and diaminobenzidine reagent (both from Gene Tech) for $1 \mathrm{~min}$. A rabbit IgG was used at the same concentration as the primary antibody as a negative isotype control. $\mathrm{HDAC}^{+}$slices were captured by Nikon microscope and described as integral optical density (IOD) per field and measured by using Image Pro-Plus 6.0. Each value represented the mean IOD \pm SEM from 3 mice.

\section{ChIP}

The ChIP assay was performed using a Millipore ChIP assay kit according to the manufacturer's protocol. The antibodies used were as follows: anti-H4K12ac (Abcam, ab46983) and normal rabbit IgG; $2 \mu \mathrm{g}$ of the specified antibody was used for each ChIP assay. PCR was performed to analyze the enrichment of sequences in DNA subjected to ChIP. The primers used for ChIP are as follows: Nur77 promoter forward: 5' GGA GCA ACT GGA GAG TGA GG 3', Nur77 promoter reverse: 5' GGG AGT GCG GAT TGT TTG 3'.

\section{Real-time qPCR}

The tissues of conditioned mice were collected at the indicated time. Naive mice were killed at the same time as the CFC 0 h group (see Fig. $3 A$ ) and the CFC $1 \mathrm{~h}$ group (see Fig. 7A). Total RNA was isolated using TRIzol-A ${ }^{+}$RNA isolation reagent (TIANGEN) following the manufacturer's protocol. Purified total RNA $(0.5 \mu \mathrm{g})$ was subsequently reverse transcribed using the ReverTra Ace qPCR RT Kit (catalog \#FSQ-101; TOYOBO) according to the manufacturer's instructions. Real-time qPCR was performed in a Cycler (Bio-Rad) using SYBR Green (Roche). The primer sequences were as follows: HDAC7 forward primer, 5' GCC TCC ATC GAC CAC TTA ACC $3^{\prime}$ and reverse primer, 5' CGA GGG TAT CTG TCG CAG TC 3'; Nur77 forward primer, 5' GAG TTC GGC AAG CCT ACC AT 3' and reverse primer, 5' GTG TAC CCG TCC ATG AAG GTG 3'; Actin forward primer, 5' CGT TGA CAT CCG TAA AGA CCT C $3^{\prime}$ and reverse primer, 5' CCA CCG ATC CAC ACA GAG TAC 3'. Each sample was assayed in duplicate, and the relative levels of mRNA were normalized for each well to the levels of the $\beta$-actin mRNA expression using the $2^{-\Delta \Delta C T}$ method.

\section{In vitro binding and ubiquitination assay}

Myc-CBX4 and HDAC7-Flag mutant proteins were expressed with a TNT Quick Coupled Transcription/Translation System (Promega) according to the manufacturer's instructions. Binding assays were performed by mixing Myc-CBX4 and HDAC7-Flag together in immunoprecipitation (IP) buffer, followed by IP with anti-Flag (Sigma-Aldrich, M8823, 1:50) and Western blot (WB) with Myc (Bethyl, A190-105A, 1:2000) antibody. Ubiquitination was analyzed with a ubiquitination kit (Boston Biochem) following the protocols recommended by the manufacturer.

\section{Sample preparation and WB}

For tissue preparation, the mice were killed $6 \mathrm{~h}$ after CFC training, context exposure alone, or shock exposure alone unless otherwise noted. Naive mice were killed at the same time as the CFC 6 h group and the CFC 0 h group (see Fig. 1A). For cell preparation, HEK293 cells were transfected with plasmids as indicated $2 \mathrm{~d}$ before lysis and cultured hippocampal neurons were treated with the indicated reagents before lysis. The samples were homogenized in ice-cold RIPA buffer, which contained 25 mм Tris- $\mathrm{HCl}, \mathrm{pH} 7.6,150 \mathrm{~mm} \mathrm{NaCl}, 1 \% \mathrm{NP}-40,1 \%$ sodium deoxycholate and $0.1 \%$ SDS with protease and phosphatase inhibitors. After grinding into homogenate and incubating for $15 \mathrm{~min}$ on ice, the extracts were centrifuged at $14,000 \times g$ for $15 \mathrm{~min}$ at $4^{\circ} \mathrm{C}$ and the supernatants were collected as total proteins. The supernatants were collected and eluted with SDS sample buffer and the proteins were resolved by SDS-PAGE. The rabbit anti-HDAC7 antibody (Sigma-Aldrich, H2662, 1:2000), the rabbit anti-CBX4 antibody (Abcam, ab174300, 1:10000), the rabbit anti-human HDAC7 ser155 (the conserved site in the mouse is ser178, Thermo, PA5-23202, 1:1000), the rabbit anti-human HDAC7 ser318 (the conserved site in the mouse is ser344, Thermo, PA5-23203, 1:1000), the rabbit anti-human HDAC7 ser448 (the conserved site in the mouse is ser480, Thermo, PA5-23384, 1:1000), the rabbit anti-Nur77 (Abcam, ab109180, 1:1000), the rabbit anti-H3K9ac, H3K14ac, H4K12ac (Abcam, ab10812, ab52946, ab46983, 1:1000), and the rabbit anti- $\beta$-actin (Sigma-Aldrich, A2066, 1:10000) were used as primary antibodies, respectively. Goat anti-rabbit secondary antibody (Calbiochem, 401353, $1: 10000$ ) was used to react with the corresponding primary antibodies. Immunoreactive bands were visualized via enhanced chemiluminescence (Pierce). A densitometry analysis of the bands was calculated using Quantity One (Version 4.6.2; Bio-Rad). 


\section{Coimmunoprecipitation (co-IP) assay}

HEK293 cells were electroporated (Amaxa Biosystems) with the indicated plasmid constructs. Forty-eight hours after the transfection, cells were harvested with RIPA buffer. The supernatant of the whole-cell lysate was precleared with protein A or G Sepharose beads at $4^{\circ} \mathrm{C}$ for $60 \mathrm{~min}$. The cleared supernatant was subsequently incubated with the indicated antibodies at $4^{\circ} \mathrm{C}$ overnight, followed by incubation at $4^{\circ} \mathrm{C}$ with protein $\mathrm{A}$ or G Sepharose beads for $2 \mathrm{~h}$. The beads were washed 4-5 times using TNE buffer and denatured in sample buffer at $95^{\circ} \mathrm{C}$ for $5 \mathrm{~min}$. The samples were subsequently detected via SDS-PAGE and immunoblotting analysis. Three independent experiments were performed.

\section{Database search of protein mass spectrum}

Raw data files were converted to Mascot Generic Format (MGF) and mzXML format using OpenMS. The MGF files were searched against the Human Swiss-Prot and common MS contaminant database using Mascot (Matrix Science) software. The tolerances for MS1 and MS2 errors were $20 \mathrm{ppm}$ and $50 \mathrm{mmu}$, respectively. Carbamidomethylation (Specificity: $\mathrm{C},+57 \mathrm{Da}$ ) was added as a fixed modification and oxidation (specificity: M, Delta: +16 Da), dimethyl (specificity: K and N-term, Delta: +28Da), and dimethyl: 2H4, 13C2 (K and N-term, Delta: +34Da) were added as variable modifications. A maximum of two trypsin miss cleavages were allowed. The instrument type selected was ESI-QTOF. The mass input was assumed to be a monoisotopic mass. A decoy search was enabled to control the false discovery rate (FDR) $<1 \%$.

Mascot search results were exported into DAT files. Together with mzXML, these DAT files were input to Trans-Proteomic pipeline (TPP) software for the quantification of lightly and heavily labeled peptides via dimethyl labeling (+6 Da on N-terminal and lysine residue). An in-housedeveloped JAVA program, which used the library of Mascot Parser from Matrix Science, was used to select peptides that have Mascot ion scores greater than the $1 \%$ FDR threshold for protein grouping. To derive the protein ratio from peptides, the TPP quantified ratios of the peptides that belong to the same protein were first globally normalized by linear leastsquares regression. The normalized ratios of each peptide were subsequently evaluated for extreme behavior using the median absolute deviation (MAD). Peptides with a ratio $<3.5 \mathrm{MAD}$ were used to derive the protein ratio. Proteins with a geometric average $\geq 2$ or $\leq 0.5$ were defined as significant change proteins and were selected for gene ontology and pathway enrichment analysis using the PANTHER and DAVID tools.

\section{Specific experiment}

Experiment 1: Effect of CFC training on the changes of HDAC7 protein levels. To detect the change of HDAC7 protein levels at different time intervals after CFC training, animals performed CFC training first. The mice were placed in a standard fear conditioning chamber and allowed to habituate for $2 \mathrm{~min}$ without stimulation (habituation). Each mouse received 3 consecutive foot shocks ( $2 \mathrm{~s}$ duration each; $0.7 \mathrm{~mA}$ ) through a stainless steel grid floor (Panlab). Each foot shock was separated by a $58 \mathrm{~s}$ time period. After an additional $58 \mathrm{~s}$ following the last shock, the mice were returned to the home cage. After CFC training, mice were killed 0,1 , $2,4,6$, and 24 h later ( $n=8$ for the $0,1,2$, and 4 h groups separately; $n=$ 9 for the 6 and 24 h groups separately). Mice in the naive group were only housed in the standard home cage during CFC training and killed at the same time as $\mathrm{CFC} 0 \mathrm{~h}$ mice $(n=8)$. The $\mathrm{DH}$ regions were then separated and proteins were extracted. We detected HDAC7 protein levels in the $\mathrm{DH}$ by WB analysis. Because we excluded the mice with abnormal behaviors during CFC training, the numbers of each group were not the same.

To observe the change of HDAC7 directly, nine mice underwent CFC training following the above procedures. Immediately or $6 \mathrm{~h}$ after CFC training, the brains were separated and sliced for the IHC staining $(n=3$ for the 0 and $6 \mathrm{~h}$ groups separately). Mice in the naive group were only housed in the standard home cage during CFC training and killed at the same time as the CFC $0 \mathrm{~h}$ mice $(n=3)$.

To further confirm the specificity of HDAC7 changes after CFC training, we not only observed the changes of HDAC7 in the VH and AMY, but also detected the changes of HDAC1 and HDAC6 protein levels in the $\mathrm{DH} 6 \mathrm{~h}$ after CFC training. Mice performed CFC training as described above and were killed at $6 \mathrm{~h}$ after CFC training $(n=4)$. Mice in the naive group were only housed in the standard home cage during CFC training and killed at the same time $(n=4)$. The $\mathrm{DH}, \mathrm{VH}$, and $\mathrm{AMY}$ regions were then removed and proteins were extracted. HDAC7 in the VH and AMY, HDAC1, and HDAC6 in the DH were detected with WB analysis.

To exclude the effect of context or shock alone on the HDAC7 protein level, mice $(n=23)$ were allowed to explore freely for $5 \mathrm{~min}$ in the training chamber without receiving a foot shock (context group, $n=6$ ); were given a $2 \mathrm{~s}$ foot shock $(0.7 \mathrm{~mA})$ immediately after being placed in the training chamber (shock group, $n=6$ ); underwent a formal CFC training (CFC group, $n=6$ ); or were only housed in the standard home cage during CFC training (naive group, $n=5$ ). All mice were killed $6 \mathrm{~h}$ after their behavioral manipulation.

Experiment 2: Effects of HDAC7 on CFC memory formation. To study the roles of HDAC7 in CFC memory, we microinjected sh-con (infection titer: $1.2 \times 10^{11}, 1 \mu$ l per side, both sides) or sh-HDAC7 lentivirus (infection titer: $1.4 \times 10^{11}, 1 \mu$ l per side, both sides) in the $\mathrm{DH}$ for 4 weeks to knock down the expression of HDAC7. Then, we detected the freezing response of the mice during CFC training (shock: $0.4 \mathrm{~mA}, n=12$ per group). After training, some of the mice ( $n=12$, randomly chosen from each group) were tested in the same context $1 \mathrm{~h}$ later and the others were tested $24 \mathrm{~h}$ later ( $n=12$ per group). These experiments were helpful for evaluating the effects of decreased HDAC7 on CFC memory formation. In addition, we microinjected Adv-con and Adv-HDAC7 in the DH for 1 week and then detected the freezing response of the mice during CFC training (shock: $0.7 \mathrm{~mA}, n=13-16$ per group). After training, some of the mice ( $n=14$, randomly chosen from each group) were tested in the same context $1 \mathrm{~h}$ later and the others were tested $24 \mathrm{~h}$ later $(n=14$ per group). These experiments were helpful for evaluating the effects of overexpressed HDAC7 on CFC memory formation.

Experiment 3: Role of ubiquitin-proteasome-dependent degradation in the decreased expression of HDAC7 after CFC training. To verify the reasons why HDAC7 decreased after CFC training, we place the infusion cannula in the DH 1 week before the behavioral experiment $(n=32)$. We microinjected $\beta \mathrm{Lac}$ (32 ng/ $\mu \mathrm{l}, 0.5 \mu \mathrm{l} /$ side, both sides), CHX $(200 \mu \mathrm{g} / \mu \mathrm{l}$, $0.5 \mu \mathrm{l} /$ side, both sides), or vehicle (DMSO, $0.5 \mu \mathrm{l} / \mathrm{side}$, both sides) in the DH 30 min before CFC training ( $n=8$ per group). The mice then performed $\mathrm{CFC}$ training and were killed $6 \mathrm{~h}$ later. Mice in the naive group were only housed in the standard home cage during CFC training and were killed at the same time as the other groups $(n=8)$. The DH was separated and $\mathrm{HDAC} 7$ protein was detected by WB analysis.

The ubiquitin-proteasome-dependent degradation of HDAC7 was detected using the DH cell lysates from mice $6 \mathrm{~h}$ after CFC training or naive treatment as described above. The lysates were immunoprecipitated by anti-HDAC7 antibodies and the ubiquitin level was detected with WB.

Experiment 4: Verification the E3 ubiquitin ligase of HDAC7. Mice in the CFC $6 \mathrm{~h}$ group were killed $6 \mathrm{~h}$ after CFC training $(n=30)$. Mice in the naive group were only housed in the standard home cage during CFC training and were killed at the same time as the CFC 6 h groups $(n=30)$. The $\mathrm{DH}$ regions were then separated out and the proteins extracted. We used anti-HDAC7 antibody to perform the IP assay. The pull-down lysates were analyzed by the protein mass spectrum (for details, see "Database search of protein mass spectrum" section). After CBX4 was selected as the candidate $\mathrm{E} 3$ ligase, co-IP assays, in vitro binding, and ubiquitination assays were performed to confirm the interaction between HDAC7 and CBX4 (for details, see the "In vitro binding and ubiquitination assay" and "Coimmunoprecipitation (co-IP) assay" sections, respectively).

Experiment 5: Roles of CBX4 in HDAC7-regulated CFC memory. The goal of this experiment was to study the roles of CBX4 in HDAC7-regulated CFC learning. We microinjected sh-con, sh-CBX4 + sh-con, or sh-CBX4 + shHDAC7 lentivirus, respectively, in the DH for 4 weeks. Then, some of the mice were tested for freezing time during CFC training $(0.7 \mathrm{~mA}, n=10$ for sh-con, $n=11$ for sh-CBX4 + sh-con, $n=11$ for sh-CBX $4+$ sh-HDAC7) to verify the roles of Nur77 in CFC learning. One hour later, the freezing times of the mice were recorded in the same context for the STM test. The other mice ( $n=10$ for sh-con, $n=11$ for sh-CBX $4+$ sh-con, $n=11$ for sh-CBX4 + sh-HDAC7) also underwent CFC training, but they were tested in the same context $24 \mathrm{~h}$ later for evaluating LTM.

Experiment 6: Effect of HDAC7 S/A and S/D mutant on its ubiquitination. The goal of this experiment was to assess the relationship between 
HDAC7 phosphorylation and its ubiquitination. We first subcloned HDAC7 S/A and HDAC7 S/D mutant constructs with mutations at 178, 344 , and 479 aa sites from serine into alanine (S/A) or aspartic acid (S/D) separately and ubiquitin and HDAC7 wild-type into pCDNA3.1 vector with Flag or HA tag in the C-terminal. We subcloned CBX4 to pEGFP-C vector. Then, we transfected these plasmids into HEK293 cells as indicated by electroporation for $48 \mathrm{~h}(2 \mu \mathrm{g}$ per plasmid, 3 million cells per group). We harvested cells with RIPA buffer and performed the co-IP assay as described in the "Coimmunoprecipitation (co-IP) assay" section. Three independent experiments were performed.

Experiment 7: Effect of HDAC7 on the acetylated modification of Nur77 during CFC memory formation. The goal of this experiment was to explore whether Nur77 was regulated by HDAC7-mediated acetylated modification. To verify the histones that regulated by HDAC7 during CFC memory, we detected the DH cell lysates from mice that had been microinjected with sh-con or sh-HDAC7 for 4 weeks and undergone CFC training for $6 \mathrm{~h}$ or were naive, as indicated in figures and described above ( $n=6$ per group). We found that H4K12ac was related to the HDAC7-involved CFC memory. To study the relationship between the increased H4K12ac and Nur77 promoter in CFC memory, we cultured hippocampal neurons for 1 week and infected with sh-con or sh-HDAC7 lentivirus into neurons for another week. Then, we harvested the neurons and performed ChIP assay (for details, see "Coimmunoprecipitation (co-IP) assay" section). Three independent experiments were performed.

Experiment 8: Roles of Nur77 in HDAC7-regulated CFC memory. The goal of this experiment was to study the roles of Nur77 in HDAC7regulated CFC learning. We microinjected sh-con, sh-Nur77 + sh-con, or sh-Nur77 + sh-HDAC7 lentivirus in the DH for 4 weeks. Then, some of the mice were tested for freezing time during CFC training $(0.7 \mathrm{~mA}$, $n=10$ for sh-con, $n=11$ for sh-Nur77 + sh-con, $n=11$ for sh-Nur77 + sh-HDAC7) to verify the roles of Nur77 in CFC learning. One hour later, the freezing times of the mice were recorded in the same context for STM test. The other mice ( $n=10$ for sh-con, $n=11$ for sh-Nur77 + sh-con, $n=11$ for sh-Nur77 + sh-HDAC7) also underwent CFC training, but were tested in the same context $24 \mathrm{~h}$ later for evaluating LTM.

Experiment 9: Effects of HDAC7 on the formation of other hippocampaldependent memories. We performed object location test and water maze test under HDAC7 knock-down or overexpression conditions to test the function of HDAC7 in the formation of hippocampal-dependent memory. For the object location test, mice were divided into four groups randomly and injected with Adv-con or Adv-HDAC7 adenovirus for 1 week or injected with sh-con or sh-HDAC7 lentivirus for 4 weeks in the DH $(n=10-12$ per group). Then, we performed the object location training. Twenty-four hours later, the mice were tested in the same arena with one object's location changed (details are described above).

For the Morris water maze test, mice were divided into four groups randomly and injected with Adv-con or Adv-HDAC7 adenovirus for 1 week or injected with sh-con or sh-HDAC7 lentivirus for 4 weeks in the DH ( $n=8$ per group). Mice were trained for 5 consecutive days and underwent a probe test (platform moved) on the sixth day (details are described above).

\section{Statistical analysis}

The data were analyzed by repeated-measures two-way ANOVA, twotailed $t$ test, one-way ANOVA, or two-way ANOVA, followed by LSD post hoc test. When equal variances were not assumed, a Dunnett's T3 test was used to compare the differences between groups. Significance was set at $p<0.05$. The results represent the means \pm SEM. Data analyses were performed using the SPSS statistical program version 18.0.

\section{Results}

\section{Spatial- and temporal-specific decrease of HDAC7 in the DH after CFC training}

CFC represents a type of hippocampal-dependent task, so we initially determined whether the HDAC7 expression was altered in the hippocampus after CFC training. The mice were killed at 0 , $1,2,4,6$, or $24 \mathrm{~h}$ after $\mathrm{CFC}$ training. The results indicated that the
HDAC7 protein level decreased significantly from 4 to $24 \mathrm{~h}$ in the $\mathrm{DH}\left(\right.$ Fig. $1 A, F_{(6,51)}=6.044, p<0.01 ; p=0.988,0 \mathrm{~h}$ vs naive, $p=$ $0.727,1 \mathrm{~h}$ vs $0 \mathrm{~h}, p=0.118,2 \mathrm{~h}$ vs $0 \mathrm{~h}, p=0.003,4 \mathrm{~h}$ vs $0 \mathrm{~h} ; p=$ $0.001,6$ h vs $0 \mathrm{~h} ; p=0.001,24 \mathrm{~h}$ vs $0 \mathrm{~h} ; 1$-way ANOVA). To show the changes of HDAC7 in the DH directly, we also performed the IHC staining in the brain slices from naive mice and conditioned mice killed early ( $0 \mathrm{~h}$ after training) and late ( $6 \mathrm{~h}$ after training). The results showed that the HDAC7 protein decreased significantly $6 \mathrm{~h}$ but not $0 \mathrm{~h}$ after CFC training in the DH (Fig. $1 B$, $F_{(2,6)}=9.499, p=0.014 ; p=0.009$ for $6 \mathrm{~h}$ vs naive, $p=0.921,0 \mathrm{~h}$ vs naive for 1-way ANOVA). However, the HDAC7 protein level in the $\mathrm{VH}$ did not change significantly $6 \mathrm{~h}$ after CFC training (Fig. $1 C, t_{(3)}^{\prime}=0.601, p=0.598,2$-tailed $t$ test). Similarly, there was no change of HDAC7 in another CFC related brain area, the Amy, $6 \mathrm{~h}$ after CFC training (Fig. $1 C, t_{(3)}^{\prime}=-1.423, p=0.250$, 2-tailed $t$ test). All of the above findings demonstrated that the decreased HDAC7 after CFC might have spatial and temporal specificity. To exclude the effect of context or shock alone on the HDAC7 protein level, the mice were separated into four groups: naive as the control group, the context-exposed group, the immediate shock group, and the CFC group. The results indicated that the HDAC7 protein levels in the DH were reduced only in the CFC group (Fig. $1 D, F_{(3,19)}=5.449, p=0.007 ; p=0.456$ for context vs naive, $p=0.695$ for shock vs naive, $p=0.002$ for CFC vs naive, $p=0.015$ for CFC vs context, $p=0.007$ for CFC vs shock, 1 -way ANOVA). It seemed that the changes of HDAC7 were related to the associative fear learning. Moreover, we detected the protein levels of two additional HDAC members, HDAC1 (one of the class I HDACs) and HDAC6 (one of the class II HDACs). The results demonstrated that there were no changes in these levels in the DH $6 \mathrm{~h}$ after CFC training (Fig. $1 E, t_{(2)}^{\prime}=0.581, p=0.602$ for HDAC6, 2-tailed $t$ test, $t_{(3)}^{\prime}=-0.14, p=0.898$ for HDAC1, 2 -tailed $t$ test), which suggested that the consolidation of CFC required the involvement of specific HDACs.

\section{HDAC7 involved in the CFC LTM formation}

To further investigate the functional roles of HDAC7 in $\mathrm{CFC}$ memory, we used Adv-HDAC7 or sh-HDAC7 to overexpress or knock down HDAC7 in the DH. The location and diffusion range of sh-HDAC7 lentivirus or Adv-HDAC7 adenovirus (both expressed GFP) in the DH are presented in Figures 2, $B$ and $F$, and effectively knocked down or increased HDAC7 expression (Fig. $2 C, t_{(6)}=33.381, p<0.001,2$-tailed $t$ test, Fig. $2 G, t_{(4)}=$ $-11.968, p<0.001,2$-tailed $t$ test). One or $24 \mathrm{~h}$ after CFC training, freezing behavior was assessed to determine the effect of HDAC7 on STM or LTM, respectively (Fig. 2A). We determined that Adv-HDAC7 or sh-HDAC7 treatment did not influence the freezing behavior during and $1 \mathrm{~h}$ after CFC training, which suggested that HDAC7 in the DH did not participate in the acquisition of CFC memory (Fig. 2D,H). However, the percentage of freezing time was independently enhanced or impaired by AdvHDAC7 or sh-HDAC7 $24 \mathrm{~h}$ after CFC training (LTM), which suggested that HDAC7 was required for the formation of CFC LTM memory (Fig. $2 I, t_{(22)}=0.758, p=0.457$ for Adv-HDAC7 vs Adv-con in STM, $t_{(21)}{ }^{\prime}=3.439, p=0.003$ for Adv-HDAC7 vs Adv-con in LTM; Fig. $2 E, t_{(29)}=-0.218, p=0.829$ for shHDAC7 vs sh-con for STM, $t_{(26)}=0.549, p=0.002$ for shHDAC7 vs sh-con for LTM, 2-tailed $t$ test). We also investigated the role of HDAC7 in the Amy in CFC and determined that both Adv-HDAC7 and sh-HDAC7 microinjection did not change the freezing value (Fig. $2 J, t_{(10)}=0.105, p=0.918$, for sh-HDAC7 vs sh-con in STM, $t_{(11)}=0.475 p=0.644$, for sh-HDAC7 vs sh-con in LTM; Fig. $2 K, t_{(11)}=-0.303, p=0.767$, for Adv-HDAC7 vs 
A
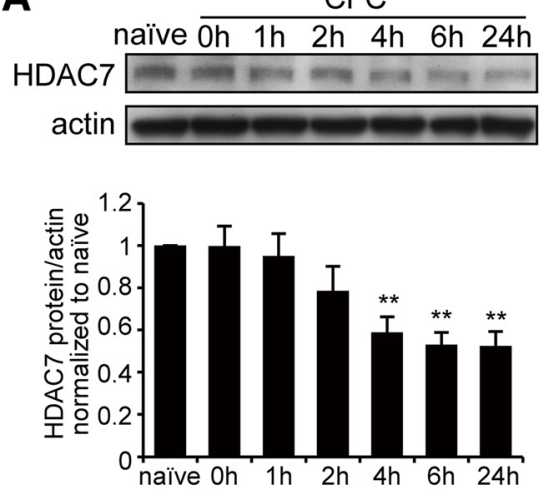

C
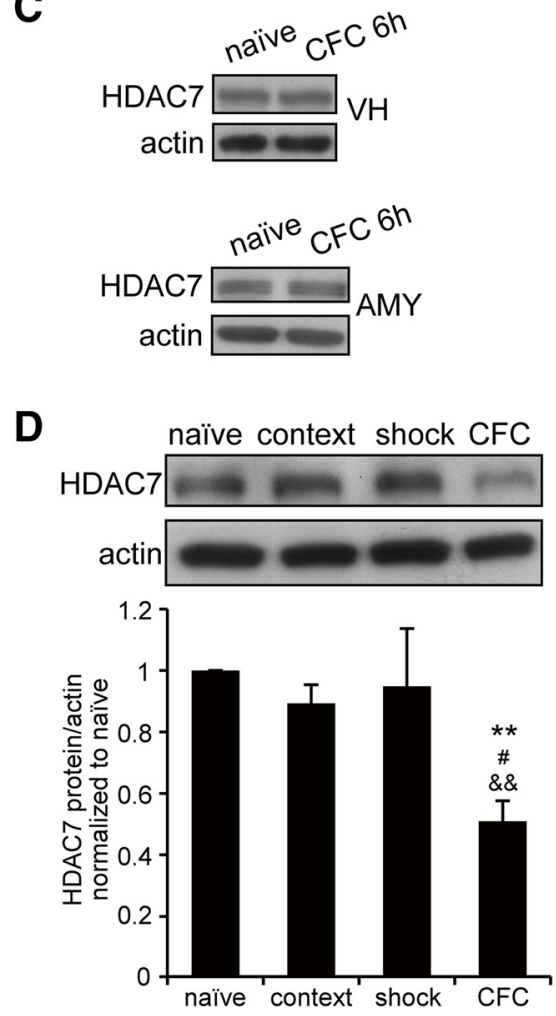

B

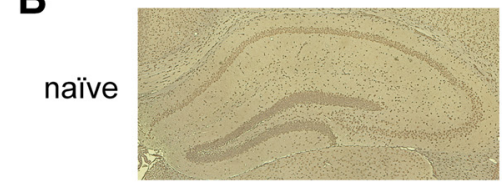

CFC Oh
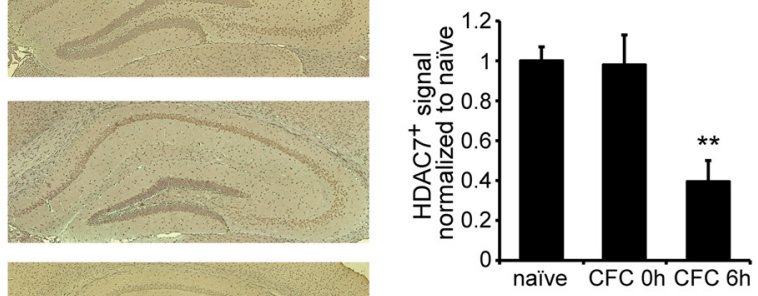

CFC 6h

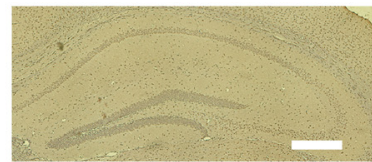

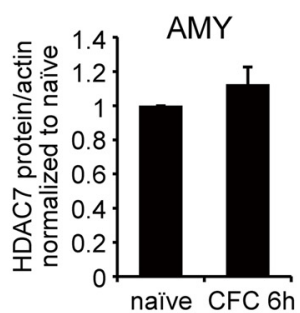

$\mathbf{E}$
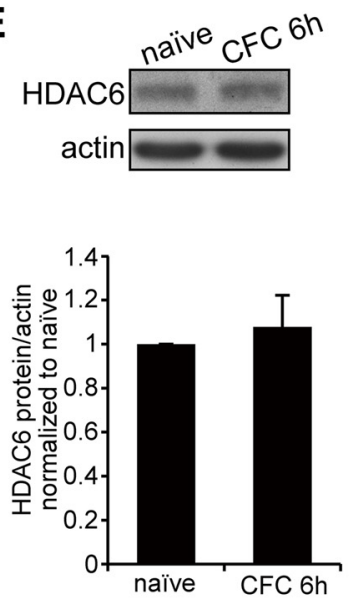
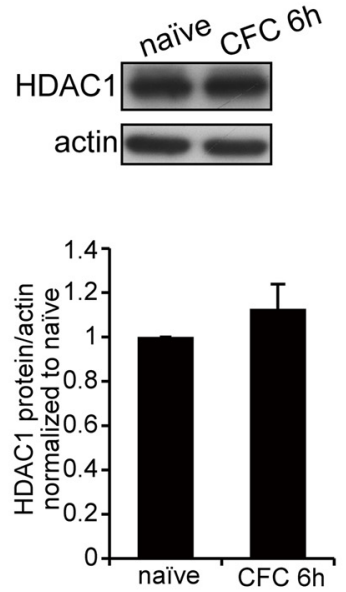

Figure 1. HDAC7 expression was decreased selectively in the DH after CFC training. $A, H D A C 7$ protein levels in the DH at different time intervals after CFC training. $n=8-9$ per time point. ${ }^{* *} p<$ 0.01 versus naive group. $B$, IHC staining showed HDAC7 in the DH. $n=3$ per group. ${ }^{* *} p<0.01$ versus naive group. $C$, HDAC7 protein levels in the VH and Amy $6 \mathrm{~h}$ after $C F C$ training. $n=4$ per group. $D$, Relative HDAC7 protein levels in the DH 6 h after context alone, immediate shock alone, or associative CFC training. $n=5-6$ per group. ${ }^{* *} p<0.01$ versus naive group; ${ }^{\#} p=0.015$ versus context; ${ }^{\&} \& p=0.007$ versus shock. E, HDAC1 and HDAC6 protein levels in the DH $6 \mathrm{~h}$ after CFC training. $n=4$ per group. All values are presented as mean \pm SEM.

Adv-con in STM, $t_{(11)}=-0.453, p=0.659$ for Adv-HDAC7 vs Adv-con in LTM, 2-tailed $t$ test). Overexpression and knockdown of HDAC7 did not affect the locomotor activity of the mice (data not shown). These findings indicated that HDAC7 in the $\mathrm{DH}$ was involved selectively in the LTM formation of CFC.

\section{Decreased HDAC7 after CFC training was related to} ubiquitin-proteasome-dependent degradation

We demonstrated that the HDAC7 protein level decreased after CFC, which may occur via two mechanisms, including the prevention of new HDAC7 protein synthesis and/or the promotion of original HDAC7 protein degradation. Therefore, we initially assessed the mRNA level of HDAC7 via qPCR assays at different time points after CFC training. The results indicated that there was no significant difference among the groups (Fig. $3 A, F_{(6,25)}=$
$0.141, p=0.944,1$-way ANOVA), which suggested that the transcription level of HDCA7 was not influenced by CFC training. We subsequently determined the effect of the degradation pathway on the HDAC7 protein level. It has been reported that HDAC7 may be degraded via the ubiquitin-proteasome pathway (Margariti et al., 2010); therefore, we initially determined whether the HDAC7 ubiquitin level changed after CFC. We demonstrated that there was a significant increase in the HDAC7 ubiquitin level $6 \mathrm{~h}$ after CFC training (Fig. 3B). We subsequently microinjected $\mathrm{CHX}$ or $\beta \mathrm{Lac}$ into the $\mathrm{DH}$ to inhibit biosynthesis and proteasome-dependent degradation, respectively. The results demonstrated that the reduction of HDAC7 after CFC training was blocked in the $\beta$ Lac-treated group, but not in the CHX-treated group, compared with the vehicle control group (Fig. $3 C, F_{(3,28)}=11.357, p=0.003 ; p<0.001$, vehicle vs 
A

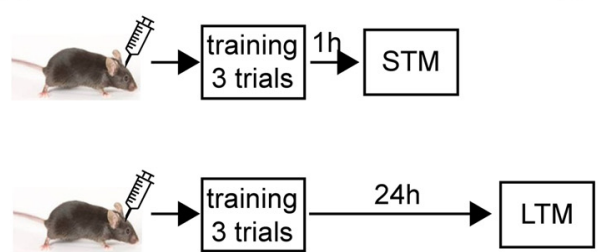

B

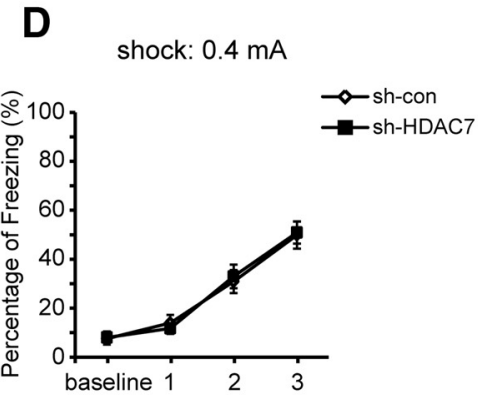

$\mathbf{E}$

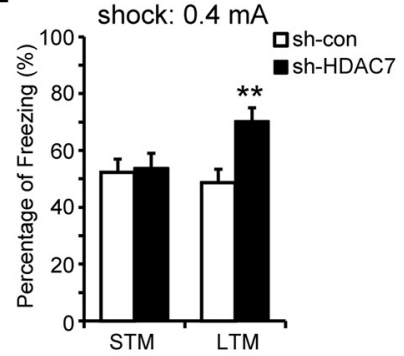

C

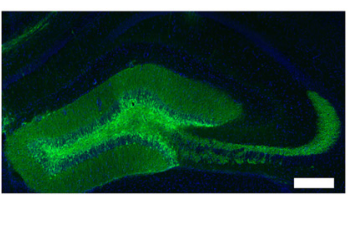

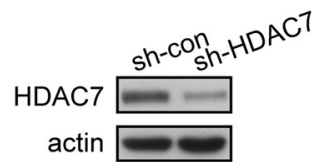

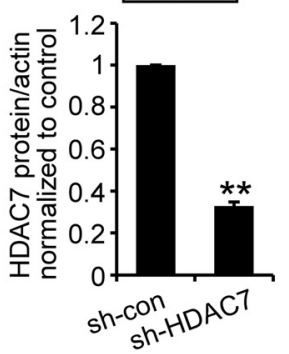

$\mathbf{F}$

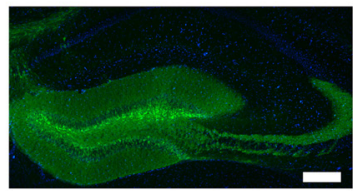

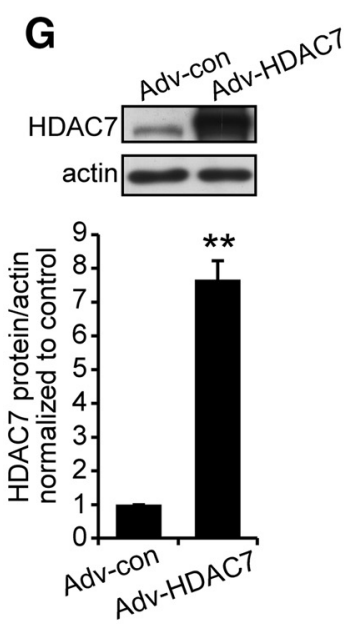

H
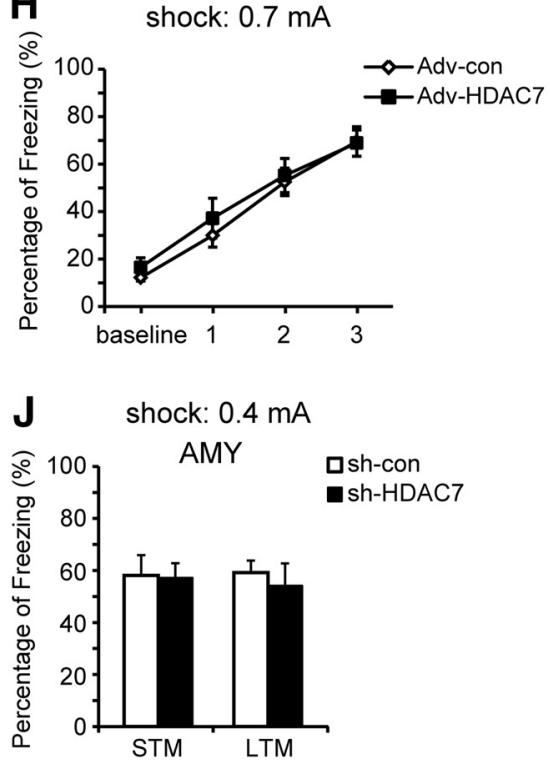

I

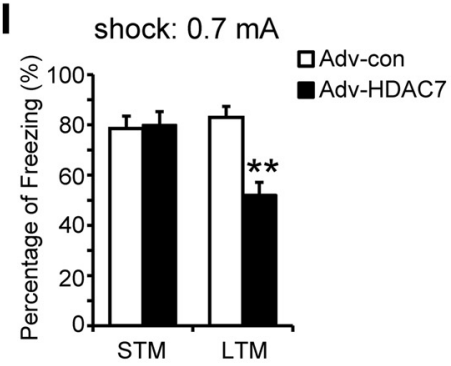

K

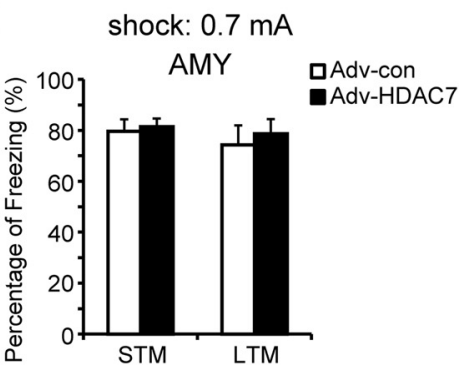

Figure 2. HDAC7 in the DH is involved selectively in CFC memory consolidation. $A$, Schematic representation of the experimental schedule to investigate the effect of HDAC7 in the DH on CFC memory formation. $\boldsymbol{B}$, Location and diffusion range of sh-HDAC7 lentivirus (GFP tag) in the DH 4 weeks after microinjection. Nuclei were stained by DAPl and are indicated in blue. Scale bar, $200 \mu \mathrm{m}$. C, Relative HDAC7 protein levels in the DH 4 weeks after scramble (sh-con) or sh-HDAC7 lentivirus injection. $n=4$ per group. ${ }^{* *} p<0.01$ versus the sh-con group. $\boldsymbol{D}$, Freezing response during CFC training. Tests were performed after lentiviruses were microinjected into the $\mathrm{DH}$ for 4 weeks. $n=24$ per group. $\boldsymbol{E}$, Freezing response $24 \mathrm{~h}$ after training. Tests were performed after lentiviruses were microinjected in the DH for 4 weeks. $n=12$ per group. ${ }^{* *} p<0.01$ versus the scramble group. $F$, Location and diffusion range of Adv-HDAC7 adenovirus (GFP tag) microinjected into the DH for 1 week. Nuclei were stained by DAPl and are indicated in blue. Scale bar, $200 \mu \mathrm{m}$. G, Relative HDAC7 protein levels in the DH after Adv-con (GFP) or Adv-HDAC7 adenovirus injection for 1 week. $n=3$ per group. ${ }^{* *} p<0.01$ versus the con group. $\boldsymbol{H}$, Freezing response in the training process. Tests were performed after Adv-HDAC7 or Adv-con injection into the DH for 1 week. $n=28$ per group. $\boldsymbol{I}$, Freezing response $24 \mathrm{~h}$ after training. Tests were performed after Adv-HDAC7 or Adv-con injection into the DH for 1 week. $n=14$ per group. ${ }^{* *} p<0.01$ versus the con group. $\boldsymbol{J}, \boldsymbol{K}, \mathrm{HDAC7}$ in Amy exhibited no effect on CFC memory consolidation. Tests were performed after lentivirus (for 4 weeks) or adenovirus (for 1 week) injection in the Amy. The freezing response 1 or $24 \mathrm{~h}$ after training. $n=5-8$ per group. All values are presented as the mean \pm SEM.

naive, $p<0.001, \beta$ Lac vs vehicle, 1 -way ANOVA). These findings indicated that decreased HDAC7 after CFC was related to ubiquitin-proteasome-dependent degradation.

\section{E3 ligase CBX4-mediated ubiquitination of HDAC7}

To determine which E3 ligase is involved in the ubiquitination of HDAC7, the mass spectrometry assay results were further analyzed. We determined that CBX4 was detected in the anti-HDAC7immunoprecipitated samples from the DH tissue. We subsequently investigated the association between HDAC7 and CBX4 using a
co-IP assay and determined that both exogenous and endogenous HDAC7 and CBX4 were associated (Fig. 4A-C). Furthermore, we purified HDAC7 and CBX4 using an in vitro transcription/translation system and identified an interaction between HDAC7 and CBX4, which may indicate that there was an association between these factors (Fig. $4 D, E$ ). The next question was whether CBX4 was the E3 ligase of HDAC7. We performed an in vitro ubiquitination assay and determined that $\mathrm{CBX} 4$ mediated HDAC7 ubiquitination, which suggested that CBX4 was the E3 ligase of HDAC7 (Fig. 4F). We subsequently investigated the function of CBX4 in vitro. The 
A

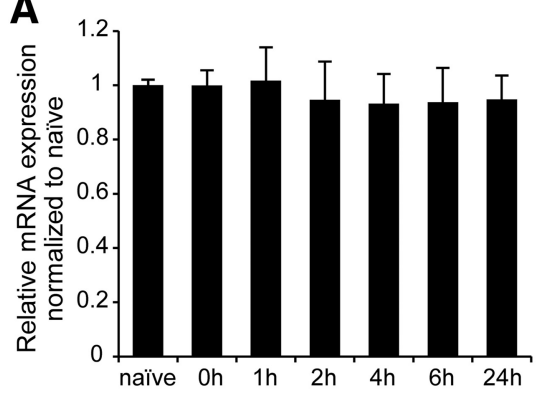

B

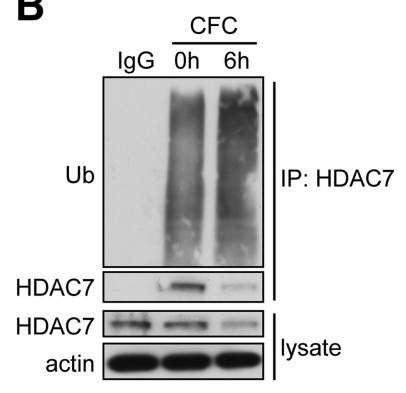

C

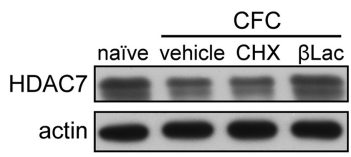

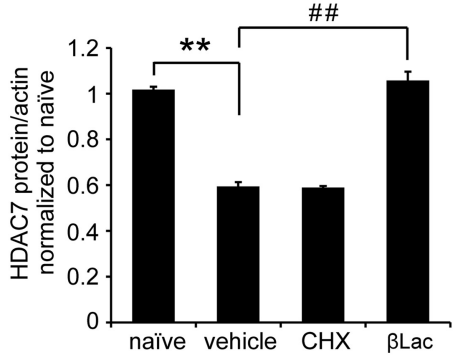

Figure 3. Decreased HDAC7 after CFC training was caused by increased ubiquitin-dependent degradation. $A$, Relative HDAC7 mRNA levels in the $\mathrm{DH}$ at different time intervals after CFC training. $n=4-5$ per group. $\boldsymbol{B}$, Ubiquitination of endogenous HDAC7 in the DH $6 \mathrm{~h}$ after $\mathrm{CFC}$ training. C, HDAC7 protein levels in the DH $6 \mathrm{~h}$ after CFC training after vehicle, $\mathrm{CHX}$, or $\beta$ Lac treatments. $n=$ 8 per group. ${ }^{* *} p<0.01$ vehicle versus naive; ${ }^{\# \#} p<0.01 \beta$ Lac versus vehicle. All values are presented as the mean \pm SEM. Three independent experiments were performed.

HDAC7 protein levels were initially detected under a CBX4 knockdown condition using the small interference RNA lentivirus that targeted CBX4 in cultured hippocampal neurons (sh-CBX4; Fig. $4 G)$, which did not affect locomotor activity and emotion. The results indicated that the HDAC7 levels significantly increased when CBX4 was downregulated (Fig. $4 G, t_{(5)}^{\prime}=-4.658, p=0.005$ for HDAC7, $t_{(4)}^{\prime}=5.399, p=0.006$ for CBX4, 2-tailed $t$ test). Moreover, we expressed $\mathrm{HDAC7}$ and ubiquitin under $\mathrm{CBX} 4$ overexpression or knock-down conditions to investigate the HDAC7 ubiquitination situation. We determined that the ubiquitination level of HDAC7 was enhanced by CBX4, which indicated that CBX4 regulated the degradation of HDAC7 (Fig. 4H).

\section{CBX4-mediated HDAC7 ubiquitination was involved in CFC consolidation}

The current findings indicated that $\mathrm{CBX} 4$, as the E3 ligase of HDAC7, promoted the degradation of HDAC7. As a result of the important roles of HDAC7 in memory, we aimed to investigate whether CBX4-mediated HDAC7 ubiquitination was also involved in CFC consolidation. The results demonstrated that the CBX4 protein level in the DH significantly increased $2-24 \mathrm{~h}$ after CFC training (Fig. $5 A, F_{(5,18)}=5.800, p=0.002 ; p=0.228$ for $1 \mathrm{~h}$ vs $0 \mathrm{~h}, p=0.015$ for $2 \mathrm{~h}$ vs $0 \mathrm{~h}, p=0.005$ for $4 \mathrm{~h}$ vs $0 \mathrm{~h}, p<0.001$ for $6 \mathrm{~h}$ vs $0 \mathrm{~h}, p=0.033$ for $24 \mathrm{~h}$ vs $0 \mathrm{~h}$, 1-way ANOVA). We subsequently microinjected sh-CBX4 into the DH to determine the effect of CBX4 on CFC memory. We initially determined that the sh-CBX4 effectively inhibited CBX4 expression and blocked the decrease of HDAC7 $6 \mathrm{~h}$ after CFC training (Fig. $5 B, t_{(8.559)}^{\prime}=$ $-3.210, p=0.011$ for HDAC7, $t_{(4.215)}^{\prime}=9.153, p<0.01$ for CBX4, 2-tailed $t$ test), which was caused by impeding the ubiquitination of HDAC7 (Fig. 5C). Moreover, sh-CBX4 treatment decreased the freezing time of the mice $24 \mathrm{~h}$ after CFC training; however, it had no effect on the freezing time during CFC training and $1 \mathrm{~h}$ after it. HDAC7 knock-down by sh-HDAC7 effectively rescued the deficit of long-term CFC memory induced by
sh-CBX4 (Fig. $5 D, E, F_{(2,29)}=0.377, p=$ 0.689 for STM, $F_{(2,29)}=10.970, p=0.003$; $p<0.001$ for sh-CBX4 vs sh-con in LTM, $p<0.001$ for sh-HDAC7 + sh-CBX4 vs sh-CBX4, 1-way ANOVA). These findings suggested that $\mathrm{CBX} 4$ regulated $\mathrm{CFC}$ memory formation via the ubiquitination of HDAC7.

\section{Conformational change was not necessary for HDAC7 ubiquitination after CFC}

It has been reported that conformational change caused by phosphorylation may influence ubiquitination (Lee et al., 2013; Berlin et al., 2013; Kitazawa et al., 2014). Moreover, the phosphorylation of one of the HDACs, HDAC5, could change its protein conformation and interact with variant molecules (Guise et al., 2014). Therefore, we investigated whether the conformational change after HDAC7 phosphorylation was necessary for the ubiquitination of HDAC7 during CFC. We initially determined that the phosphorylation levels of three sites $(178,344$, and 479 ) increased $4 \mathrm{~h}$ after $\mathrm{CFC}$ training (Fig. $6 A, F_{(5,18)}=4.954, p=0.001 ; p=$ 0.014 for $1 \mathrm{~h}$ group, $p=0.002$ for $2 \mathrm{~h}$ group, $p=0.007$ for $4 \mathrm{~h}$ group, $p<0.001$ for 6 h group for $\mathrm{p}-178 ; F_{(5,22)}=6.198, p=$ $0.001 ; p=0.007$ for 1 h group, $p=0.004$ for 2 hroup, $p<0.001$ for $4 \mathrm{~h}$ group, for $\mathrm{p}-344 ; F_{(5,23)}=5.489, p=0.002 ; p=0.009$ for $1 \mathrm{~h}$ group, $p=0.001$ for $2 \mathrm{~h}$ group, $p<0.001$ for $4 \mathrm{~h}$ group, $p=$ 0.001 for 6 h group for p-479, 1-way ANOVA). We subsequently attempted to assess the relationship between the phosphorylation and ubiquitination of HDAC7. We constructed a constitutively unphosphorylated mutant (mutated at all three phosphorylation sites, HDAC7 S/A) and a constitutively phosphorylated mutant (mutated at all three phosphorylation sites, HDAC7 S/D) and transfected them into HEK293 cells. The results demonstrated that the ubiquitination level of HDAC7 was not significantly different after constitutively unphosphorylated or constitutively phosphorylated treatments (Fig. 6B). Moreover, the interaction of CBX4 and HDAC7 was not influenced by the phosphorylation of HDAC7 in HEK293 (Fig. 6C). These findings suggested that HDAC7 phosphorylation did not participate in the ubiquitin degradation process of HDAC7.

\section{Nur77 was involved in CFC consolidation as a target gene of HDAC7}

Nur77 has been reported to be inhibited by HDAC7 and this inhibitory action is controlled by the subcellular localization of HDAC7 (Dequiedt et al., 2003, 2005; Parra et al., 2007). Therefore, we aimed to determine whether the role of HDAC7 in CFC memory formation was mediated via Nur77. We first performed qPCR to detect the changes of Nur77 at different time points after CFC training. The results showed that Nur77 expression in the $\mathrm{DH}$ increased significantly $1 \mathrm{~h}$ after CFC training and returned to baseline $4 \mathrm{~h}$ later. By $6 \mathrm{~h}$ after CFC training, the Nur77 mRNA levels had the second increase, which lasted until $24 \mathrm{~h}$ after CFC training. Forty-eight hours after conditioning, Nur77 expression was back to normal baseline levels again (Fig. $7 A, F_{(5,18)}=12.509$, $p<0.001 ; p<0.001$ for $1 \mathrm{~h}, p=0.187$ for $4 \mathrm{~h}, p=0.009$ for $6 \mathrm{~h}$, 
A

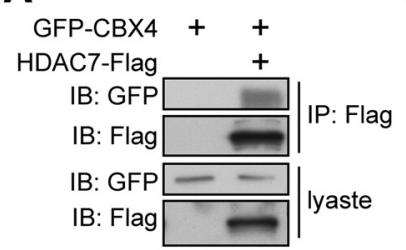

B

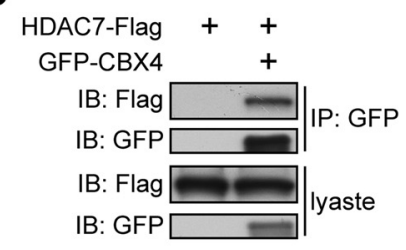

C

IP: IgG HDAC7

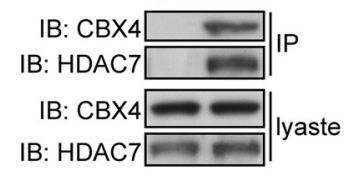

D

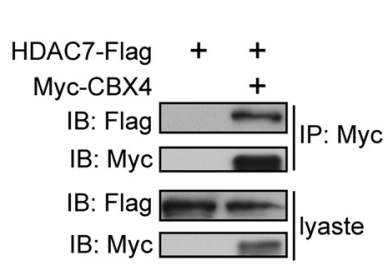

$\mathbf{E}$

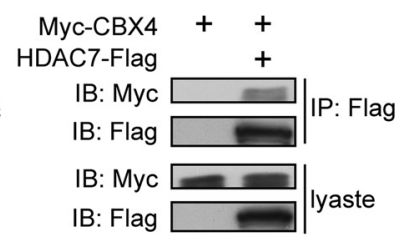

$\mathbf{F}$

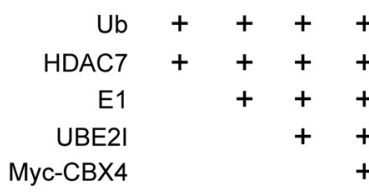

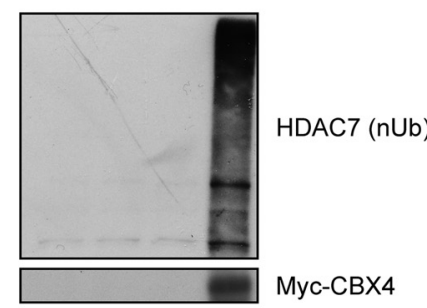

G
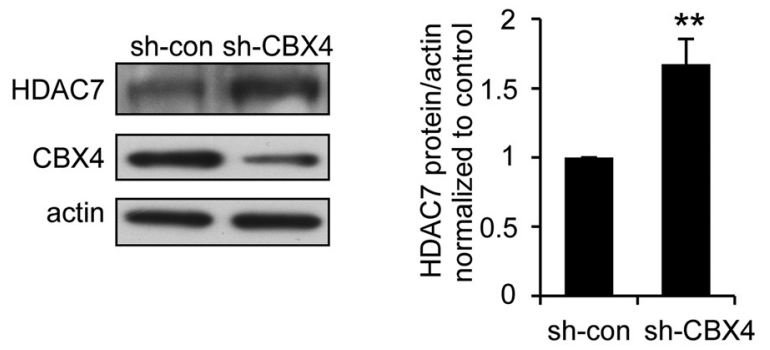

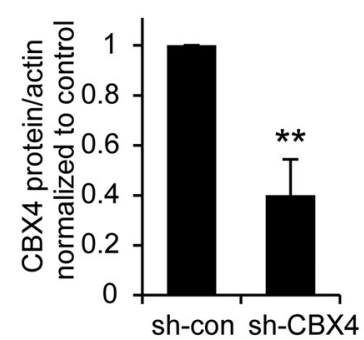

$\mathbf{H}$

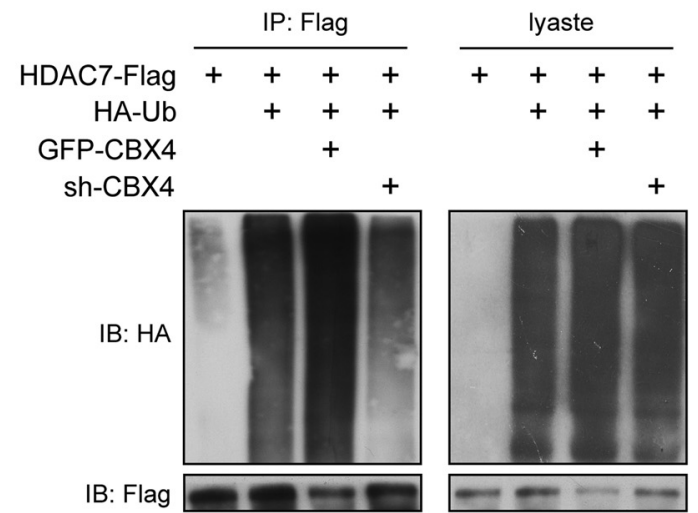

Figure 4. E3 ligase CBX4-mediated ubiquitination of HDAC7.A, B, Co-IP was performed in HEK293 cells that expressed HDAC7 and CBX4. Cell lysates were immunoprecipitated with anti-Flag or anti-GFP antibodies as indicated and analyzed via immunoblotting. C, Endogenous Co-IP was performed in the DH. The DH lysates were immunoprecipitated with anti-HDAC7 antibodies and analyzed via immunoblotting. A preimmunized lgG (rabbit) was used as a negative control. D, E, Direct binding analysis of HDAC7 and CBX4. HDAC7 and CBX4 were purified with the TNT Quick Coupled Transcription/Translation System (see Materials and Methods for details). Mixed lysates that contained HDAC7 and CBX4 were immunoprecipitated with anti-myc or anti-Flag antibodies and analyzed via immunoblotting. $\boldsymbol{F}$, Purified proteins by the TNT Quick Coupled Transcription/Translation System (refer to the Materials and Methods for details) were mixed as indicated and the ubiquitination levels were assessed via immunoblotting. G, HDAC7 protein levels under sh-con or sh-CBX4 conditions in cultured hippocampal neurons. $n=5-6$ per group. ** $p<0.01$ sh-CBX4 versus sh-con. $\boldsymbol{H}$, Ubiquitination levels of HDAC7 under CBX4 overexpression or knock-down conditions. HEK293 cell lysates that expressed HDAC7, Ub, CBX4, or sh-CBX4 as indicated were immunoprecipitated with anti-Flag antibodies and immunoblotting was perform using the indicated antibodies. All values are presented as the mean \pm SEM. Three independent experiments were performed.

$p=0.005$ for $24 \mathrm{~h}, p=0.132$ for $48 \mathrm{~h}$ for the $\mathrm{DH} ; F_{(5,23)}=0.205$, $p=0.975$ for the $\mathrm{VH})$. Accordingly, the protein level of Nur77 increased significantly 6 and $24 \mathrm{~h}$ after CFC and decreased back to baseline $48 \mathrm{~h}$ later in the $\mathrm{DH}$. The changes of HDAC7 protein moved inversely to the Nur77 protein at the same time in the DH(Fig. $7 B, F_{(3,12)}=30.946, p<0.001 ; p<0.001$ for $6 \mathrm{~h}, p<$ 0.001 for $24 \mathrm{~h}, p=0.969$ for $48 \mathrm{~h}$ for HDAC7 in the DH; $F_{(3,10)}=$ $16.330, p<0.001 ; p<0.001$ for $6 \mathrm{~h}, p=0.003$ for $24 \mathrm{~h}, p=0.648$ 
A

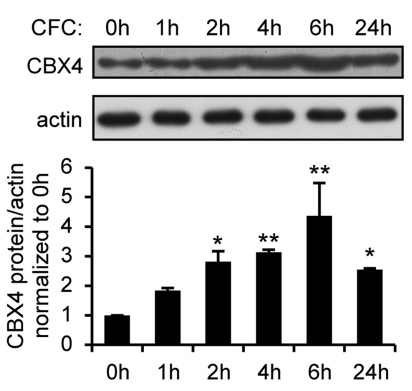

C
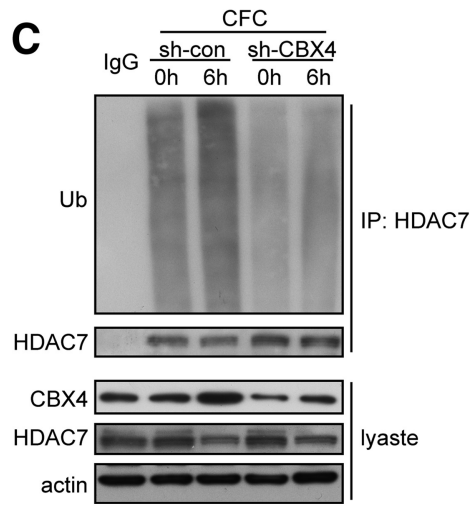

B
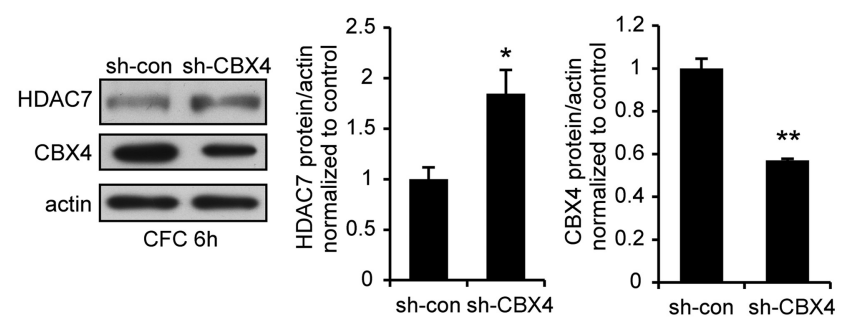

D

\section{E}

shock: $0.7 \mathrm{~mA}$

ash-con

ash-CBX4+sh-con
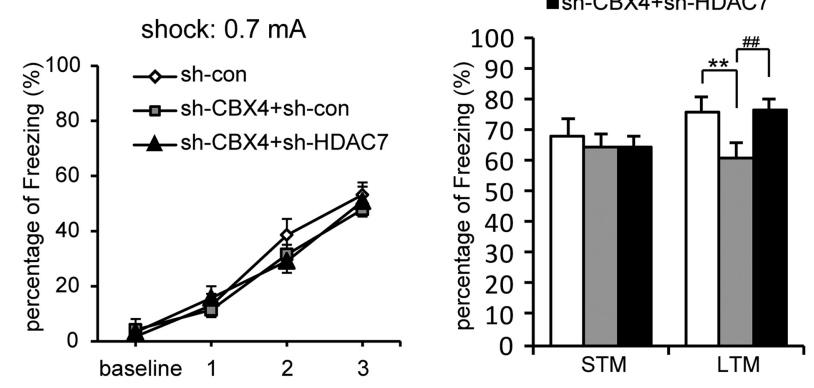

Figure 5. CBX4 regulated the degradation of HDAC7 during CFC. $A, C B X 4$ protein level in the DH at different time intervals after CFC training. $n=4$ per time point. ${ }^{*} p<0.05$; ${ }^{* *} p<0.01$ versus naive control. $B$, HDAC7 protein levels under sh-con or sh-CBX4 conditions 6 h after CFC. $n=4-7$ per group. ${ }^{*} p<0.05 ;{ }^{* *} p<0.01$ sh-CBX4 versus sh-con. C, Change in HDAC7 ubiquitination levels under CBX4 control or knock-down conditions at 0 or $6 \mathrm{~h}$ after $\mathrm{CFC}$ training. The DH lysates were immunoprecipitated with anti-HDAC7 antibodies and detected via immunoblotting. $D$, Freezing response of different groups during CFCtraining. $n=10-12$ per group. $E$, Freezing response $1 \mathrm{~h}(\mathrm{STM})$ or $24 \mathrm{~h}(\mathrm{LTM})$ after training for different groups. $n=10-12$ per group. ${ }^{* *} p<0.01$ sh-CBX4 + sh-con versus sh-con; $\# p<0.01$ sh-con + sh-HDAC7 versus sh-CBX4 + sh-con. All values are presented as the mean \pm SEM.

for $48 \mathrm{~h}$ for Nur77 in the $\mathrm{DH}, 1$-way ANOVA), but not in the $\mathrm{VH}$ (Fig. $7 B, F_{(3,12)}=0.316, p=0.901$ for HDAC7 in the $\mathrm{VH} ; F_{(3,12)}=$ $0.679, p=0.814$ for Nur77 in the VH, 1-way ANOVA). HDAC7 regulated target genes expression via deacetylating histones (Chen et al., 2009).

We next assessed the changes of histone acetylation after CFC. We found that the acetylation of $\mathrm{H} 3 \mathrm{~K} 9, \mathrm{H} 3 \mathrm{~K} 14$, and $\mathrm{H} 4 \mathrm{~K} 12$ increased significantly $6 \mathrm{~h}$ after CFC training, but only H4K12 acetylation (H4K12ac) was upregulated by sh-HDAC7 treatment (Fig. $7 C$, for HDAC7, CFC training, $F_{(1,11)}=6.045, p=0.039$, group, $F_{(1,11)}=26.659, p=0.001$; for $\mathrm{H} 3 \mathrm{~K} 9 \mathrm{ac}$, CFC training, $F_{(1,11)}=36.901, p<0.001$, group, $F_{(1,11)}=0.003, p=0.960$; for H3K14ac, CFC training, $F_{(1,11)}=16.908, p=0.003$, group, $F_{(1,11)}=$ $0.135, p=0.723$; for H4K12ac, CFC training, $F_{(1,11)}=45.768$, $p<0.001$, group, $F_{(1,11)}=39.659, p<0.001 ; 2$-way ANOVA). Therefore, we performed the CHIP assay further to study the relationship between the increased H4K12ac and Nur77 promoter. The results showed that H4K12ac bound more with Nur77 under the sh-HDAC7 condition compared with sh-con group (Fig. 7D). All of these results suggested that HDAC7 might regulate the Nur77 expression via changing the H4K12 acetylation during CFC memory formation. In the following, we observed the changes of Nur77 protein through regulating the quantity of HDAC7. The results showed that sh-HDAC7 treatment could increase the expression of Nur77 significantly $6 \mathrm{~h}$ after CFC training (Fig. $7 E, F_{(2,11)}=74.395, p<0.001 ; p=0.002$ for sh-con vs naive, $p<0.001$ for sh-HDAC7 vs sh-con for Nur77, $F_{(2,13)}=170.98, p<0.001 ; p<0.001$ for sh-con vs naive, $p<0.001$ for sh-HDAC7 vs sh-con for HDAC7, 1-way ANOVA) and the roles of Adv-HDAC7 were the opposite (Fig. $7 E, F_{(2,18)}=$ $112.361, p<0.001 ; p<0.001$ for Adv-con vs naive, $p<0.001$ for
Adv-HDAC7 vs Adv-con for Nur77, $F_{(2,18)}=77.416, p<0.001$; $p=0.007$ for Adv-con vs naive, $p<0.001$ for Adv-HDAC7 vs Adv-con for HDAC7, 1-way ANOVA). Moreover, we found that sh-Nur77 treatment decreased the percentage of freezing significantly $24 \mathrm{~h}$ after CFC training, but had no effects during and $1 \mathrm{~h}$ after CFC. The blocked effects of sh-Nur77 on CFC LTM could also not be rescued by sh-HDAC7 treatment (Fig. $7 F, G, F_{(2,30)}=$ 3.238, $p=0.05 ; p=0.018$ for sh-Nur77 vs sh-con, $p=0.59$ for sh-Nur77 + sh-HDAC7 vs sh-Nur77, 1-way ANOVA). These results suggested that Nur77 is one of the target genes of HDAC7 involved in CFC memory.

\section{HDAC7 contributed to the formation of hippocampal- dependent memory procedures}

HDAC7 in the DH contributed to the formation of long-term memory; therefore, we subsequently aimed to determine whether the role of HDAC7 is specific in the CFC procedure. We implemented two additional hippocampal-dependent memory procedures, including the object location test and Morris water maze, for further evaluation. We initially assessed the time the animal searched for an object and determined that there was no difference between the HDAC7 overexpression or knock-down groups with the corresponding control groups (Fig. 8A, object location training, $p=0.775$ for Adv-HDAC7, $p=0.968$ for sh-HDAC7). However, HDAC7 overexpression significantly decreased the discrimination index in the object location test (Fig. $8 A, t_{22}=7.047$, $p<0.001$ for Adv-HDAC7 in object location test, 2-tailed $t$ test) and vice versa (Fig. $8 A, t_{(12.102)}{ }^{\prime}=-4.530, p<0.001$ for shHDAC7 group in object location test, 2-tailed $t$ test). Moreover, HDAC7 overexpression increased the escape latency time from the second to fifth training days (Fig. $8 B$, training days, $F_{(4,60)}=$ 
A

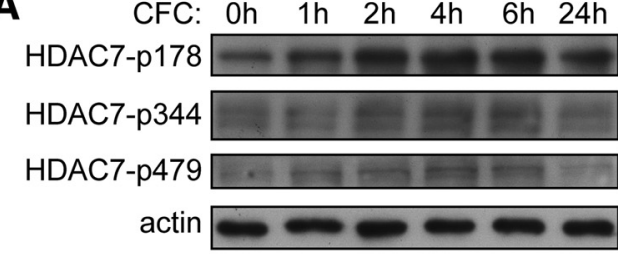

B

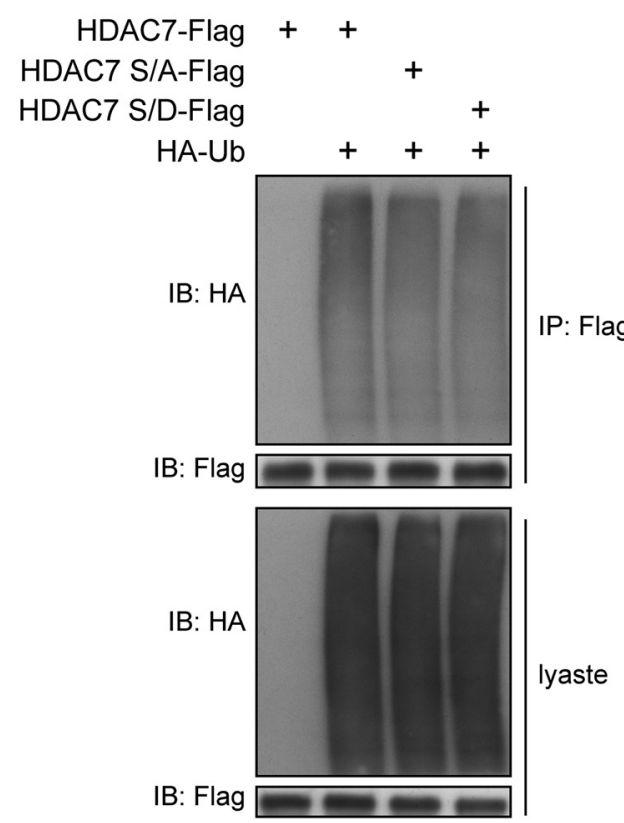

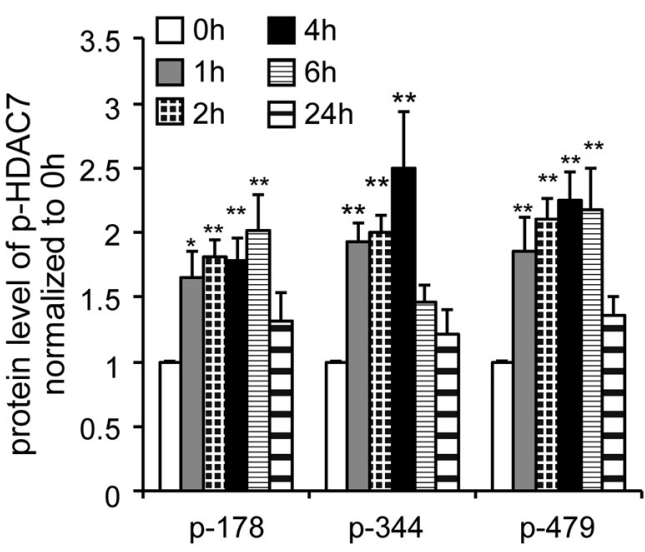

C

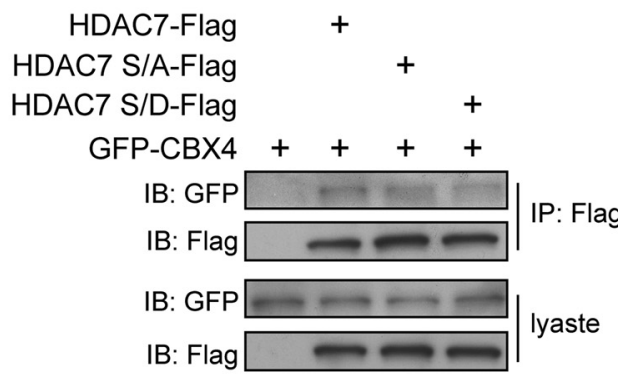

Figure 6. Changes in HDAC7 ubiquitination after CFC were not related to conformational change of HDAC7 by phosphorylation. $A, H D A C 7$ phosphorylation levels in the DH were detected via immunoblotting at the indicated time intervals after CFC. $n=5-6$ per group. ${ }^{*} p<0.05 ;{ }^{* *} p<0.01$ versus $0 \mathrm{~h}$. B, Effect of HDAC7 S/A mutant on its ubiquitination. Ubiquitination levels of HDAC7 and its mutants were detected in HEK293. C, Effect of HDAC7 S/A mutant in its association with CBX4. All values are presented as the mean \pm SEM. Three independent experiments were performed.

$45, p=0.02$; group, $F_{(1,60)}=5.39, p=0.03$; training days $\times$ group, $F_{(4,60)}=8.779, p=0.01$, repeated-measures ANOVA) and decreased the time spent in the target quadrant in the water maze probe test (Fig. $8 C, t_{(17)}=3.452, p=0.003,2$-tailed $t$ test) and vice versa (Fig. $8 D, F_{(4,60)}=40.101, p=0.01$; group, $F_{(1,60)}=$ $11.33, p=0.004$; training days $\times$ group, $F_{(4,60)}=31.650, p<$ 0.01 , repeated-measures ANOVA, Fig. $8 E, t_{(19)}=-4.492, p<$ $0.001,2$-tailed $t$ test). These findings suggested that HDAC7 was involved in the long-term memory formation of most types of hippocampal-dependent procedures.

\section{Discussion}

We demonstrated that HDAC7 in the $\mathrm{DH}$ negatively regulated the consolidation of CFC long-term memory. We subsequently demonstrated that the reduction of HDAC7 in the DH after CFC was regulated by ubiquitin-related degradation, which was not affected by HDAC7 phosphorylation. Moreover, CBX4 was one of the E3 ligases and Nur77 was one of the target genes of HDAC7 during memory formation. In addition to the roles in CFC, overexpressing or knocking down HDAC7 in the DH could block or facilitate the formation of other hippocampal-dependent memory, including the Morris water maze and object location test.

\section{Decreased HDAC7 in the DH involved in CFC formation}

Using in situ hybridization, previous studies showed that HDAC7 mRNA expressed in the granule cell layer of the DH for C57BL6J mice and in almost all the hippocampal neurons of rat (Broide et al., 2007; Jagirdar et al., 2016). These results are consistent with our finding that $\mathrm{HDAC} 7$ protein presented extensively in the $\mathrm{DH}$ by WB (Fig. 1A) and immunohistochemical staining (Fig. 1B). The subtle difference of HDAC7 distribution in the DH may be related with the different species and detection methods. We identified several novel insights in this study regarding the function and mechanism of HDAC7 in CFC memory formation. First, our results demonstrated that consolidation of CFC memory relied critically on the decrease of HDAC7 protein level selectively in the $\mathrm{DH}$ during the late posttraining period. Previous reports have demonstrated that both the hippocampus and the Amy are involved in CFC memory formation (Huff and Rudy, 2004; McGaugh, 2004), whereas no changes and uselessness of HDAC7 regulation in the Amy and the VH were found during CFC. In addition, there were no changes of HDAC1 and HDAC6 protein levels in the DH $6 \mathrm{~h}$ after CFC training, whereas HDAC7 decreased significantly. Those results suggested that the consolidation of CFC training might not need the involvement of HDAC1 and HDAC6 and are consistent with previous reports that knocked-out HDAC1 or HDAC6 did not interfere with the CFC memory (Bahari-Javan et al., 2012; Govindarajan et al., 2013). All of these results indicated that the roles of HDAC7 had spatial specificity in CFC memory. Second, the reduction of HDAC7 protein levels in the DH was only found after associative context-shock pairings, but not after the exposure to the context or shock alone, which suggests that the interaction of the CS and 
A
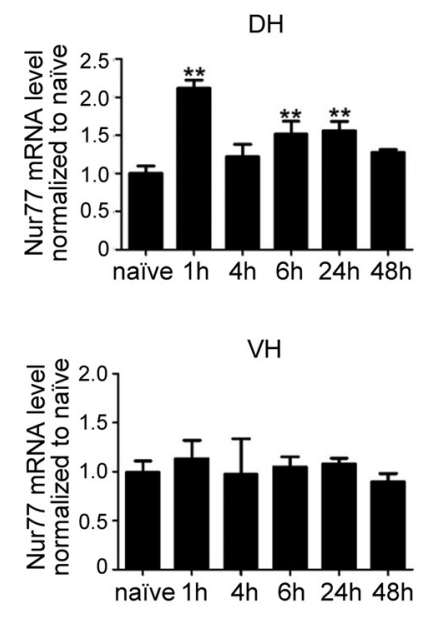

C

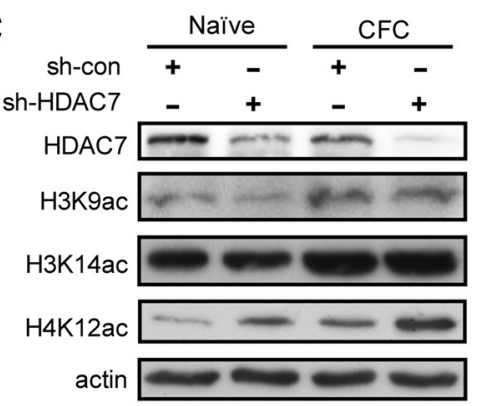

E

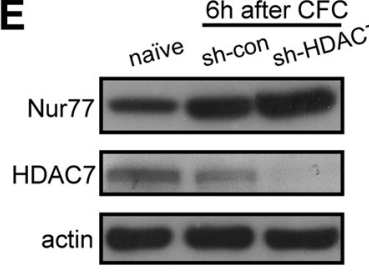

6 h after CFC

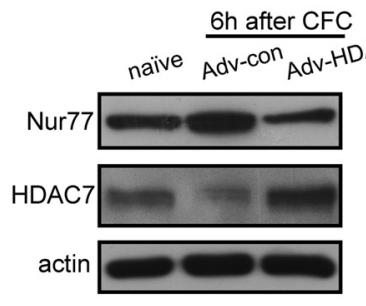

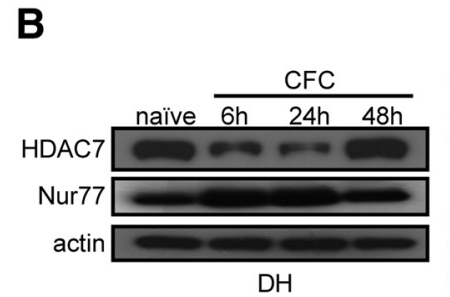
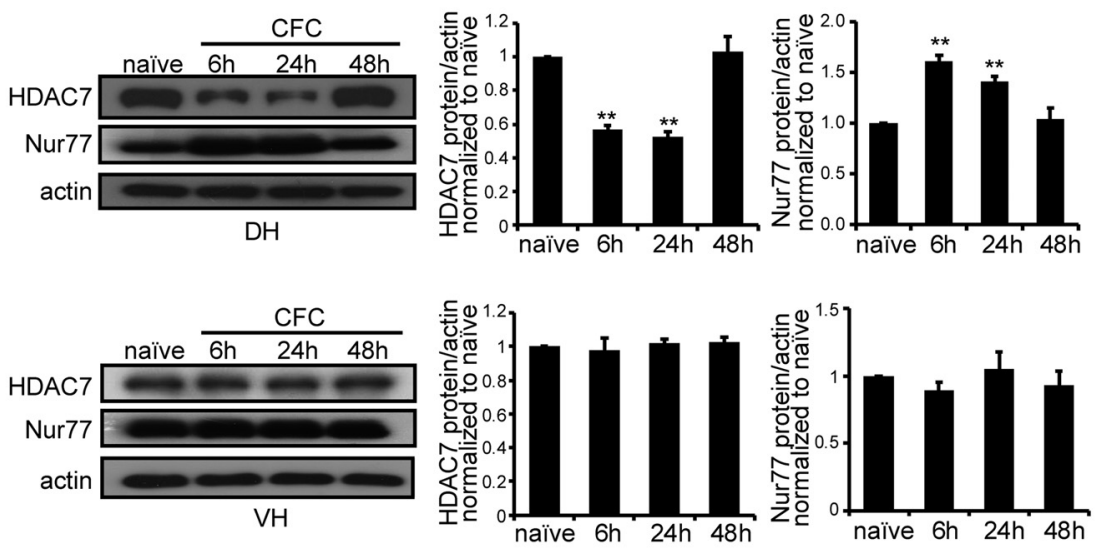

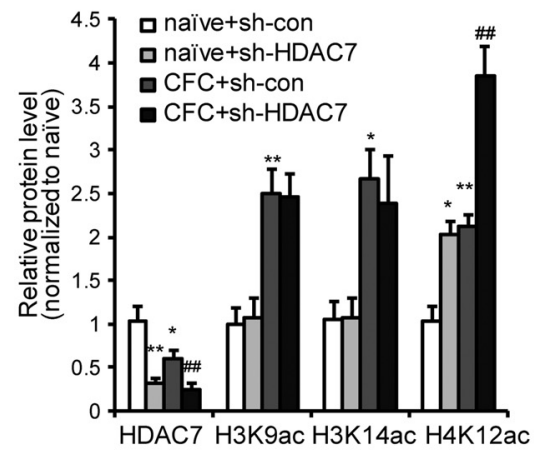

F

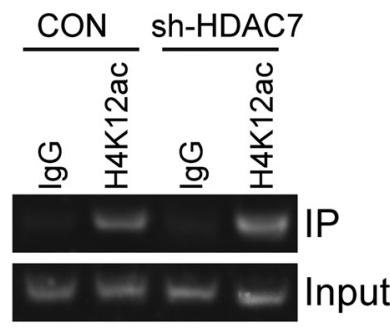

Nur77 promoter shock: $0.7 \mathrm{~mA}$

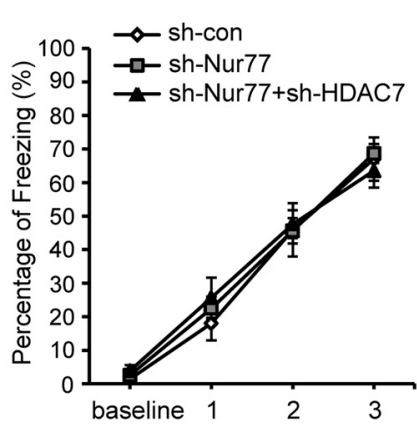

G

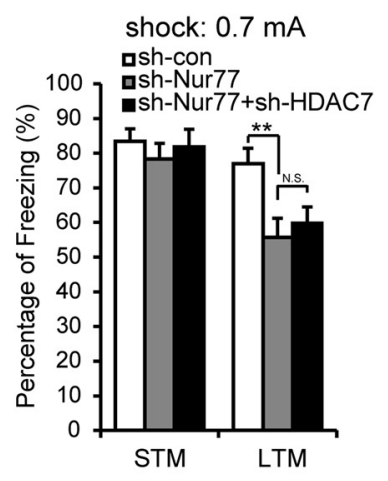

Figure 7. Nur77 was the target gene of HDAC7 in CFC. $A$, Nur77 mRNA level after CFC. ${ }^{* *} p<0.01$ versus naive. $B$, HDAC7 and Nur77 protein levels after CFC. ${ }^{* *} p<0.01$ versus naive. $C$, Changes of histone acetylization $6 \mathrm{~h}$ after CFC. ${ }^{*} p<0.05$ versus naive + sh-con; ${ }^{* *} p<0.01$ versus naive + sh-con; ${ }^{\# \#} p<0.01$ versus CFC + sh-con. $D$, Binding between H4K12ac and Nur77 promoter by CHIP assay. $\boldsymbol{E}$, Changes of Nur77 after CFC training under HDAC7 knock-down or overexpression treatment. $n=4-7$ per group. ${ }^{* *} p<0.01$ versus naïve; ${ }^{\# \#} p<0.01$ versus Adv-con. $\boldsymbol{F}$, Freezing response during CFC training. $n=10-12$ per group. G, Freezing response $1 \mathrm{~h}(\mathrm{STM})$ or $24 \mathrm{~h}(\mathrm{LTM})$ after training. $n=10-12$ per group. ${ }^{* *} p<0.01$ versus sh-con. All values are presented as the mean \pm SEM.

US is obligatory for HDAC7 decrease. The hippocampus is the key area for the forming of contextual representations (Rudy et al., 2002). The context alone is power enough to trigger some molecules to change in the hippocampus (Huff and Rudy, 2004; Lopez-Fernandez et al., 2007). However, in our study, the context alone did not change the expression of HDAC7, which suggested that changed HDAC7 was not involved in the contextual representation. Finally, HDAC7 regulation could interfere with other hippocampal-dependent memory, which demonstrated that HDAC7 may have general roles in this type of memory. Interestingly, when mice performed object location training $24 \mathrm{~h}$ after $\mathrm{CFC}$ (the time that the protein levels of HDAC7 decreased significantly), the discrimination index tended to increase in the object location test $(p=0.063)$. Combined with the results obtained from the sh-HDAC7-treated mice in the object location test, HDAC7 was undoubtedly involved in this hippocampal-de- 
A
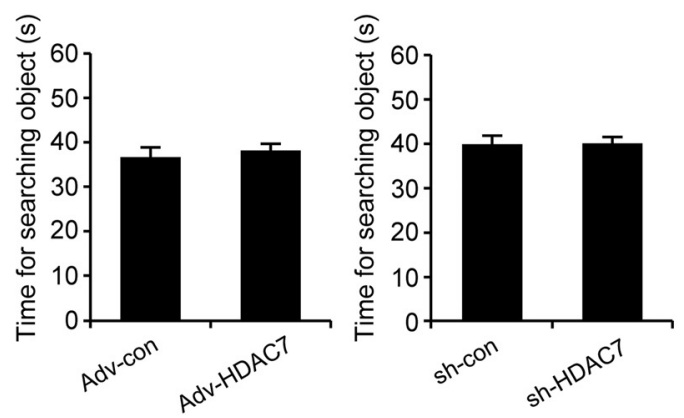

B

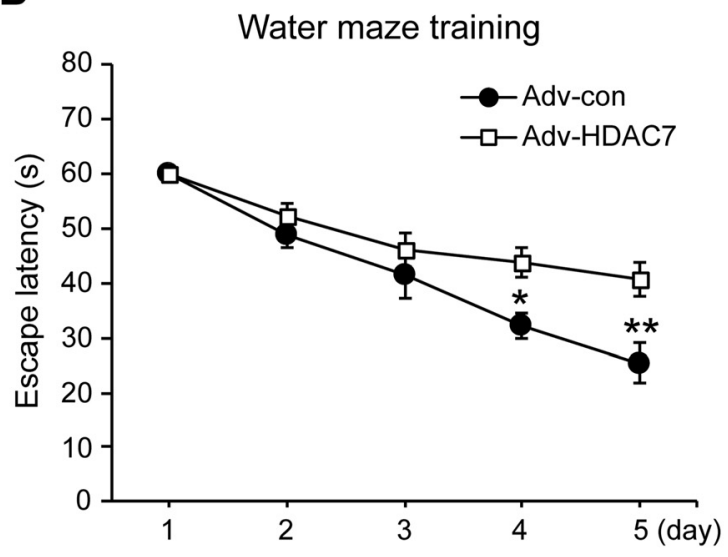

D

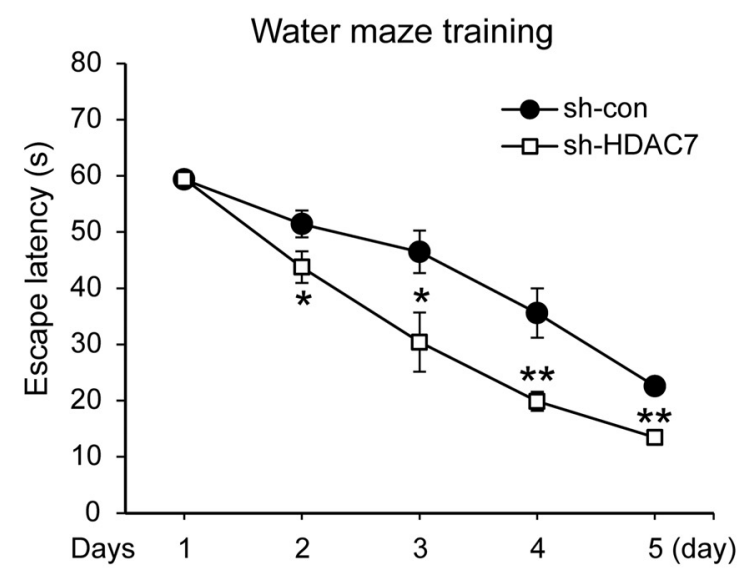

Object location test
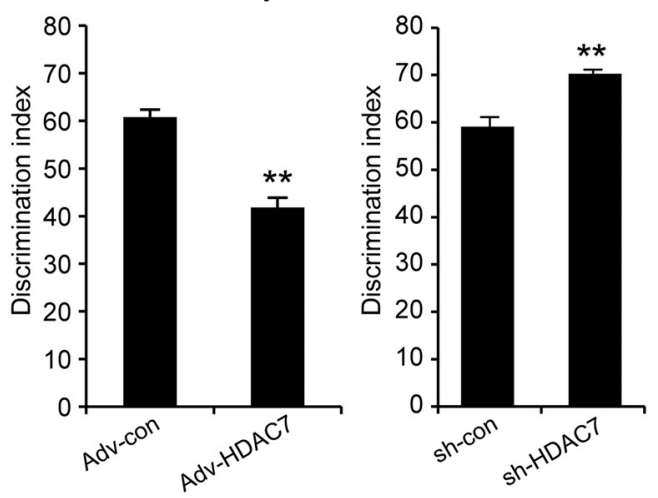

C

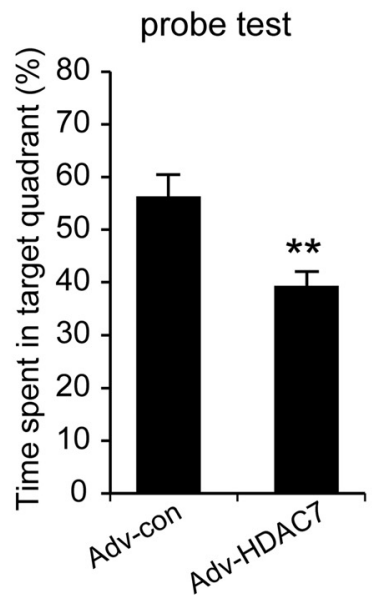

$\mathbf{E}$

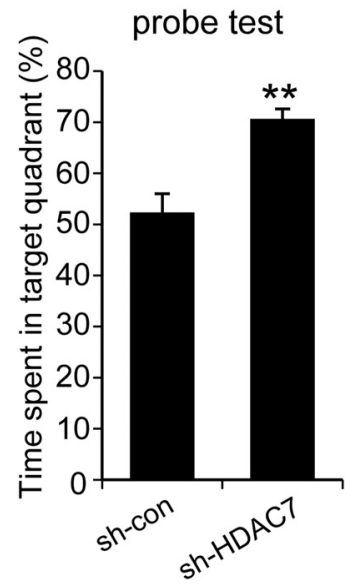

Figure 8. HDAC7 is involved in the formation of hippocampal-dependent memory. $A$, Virus with shRNA or overexpressed HDAC7 was independently microinjected into the DH and the times for searching the object and for object location were assessed. $n=10-12$ per group. ${ }^{* *} p<0.01$ sh-HDAC7 or Adv-HDAC7 versus sh-con or Adv-con. $B, D$, Escape latency to find the hidden platform in the water maze test. $n=8$ per group. ${ }^{*} p<0.05 ;{ }^{* *} p<0.01$ sh-HDAC7 or Adv-HDAC7 versus sh-con or Adv-con. $C, E$, Time spent in the target quadrant in the probe test. $n=8$ per group. $*^{* *} p<0.01$ sh-HDAC7 or Adv-HDAC7 versus sh-con or Adv-con. All values are presented as the mean \pm SEM.

pendent memory, but the size of effects on the behaviors might attribute to the decreased degree of HDAC7. We have to point out that we cannot exclude the effect of HDAC7 on the retrieval of CFC memory because the roles of sh-HDAC7 or Adv-HDAC7 viruses lasted for a long time.
Decreased HDAC7 in CFC was caused primarily by a ubiquitin-dependent degradation pathway

We further investigated the mechanism of decreased HDAC7 in CFC and determined that degradation, but not synthesis, significantly changed in CFC training, which suggests that HDAC7 was 
regulated through the degradation pathway in $\mathrm{CFC}$. It has been reported that HDAC7 mRNA expression level decreased in microarray analysis (Gupta-Agarwal et al., 2012); however, our result showed that there was not a significant change in the HDAC7 mRNA level during CFC. The reason for this inconsistency might be the different study subjects. Gupta-Agarwal et al.'s (2012) microarray analysis tested the CA1 of rat, whereas we detected the $\mathrm{DH}$ of mice. It has been reported that HDAC2 maintained stability via ubiquitin and deubiquitin circulation in cancer (Li et al., 2016), whereas HDAC9 increased synthesis in a brain ischemic model (Shi et al., 2016). In contrast to these HDACs, HDAC7 functioned via a ubiquitin-dependent degradation pathway in the CNS, which is consistent with the cardiovascular system (Li et al., 2004; Chang et al., 2006). Similarly, a previous study indicated that HDAC2 and HDAC1 were also degraded via a ubiquitination pathway (Canettieri et al., 2010; Li et al., 2016). HDAC7 has been reported to be degraded via a ubiquitination pathway. Moreover, we screened CBX4, which has E3 ligase activity, regarding its interaction with HDAC7. CBX4 is widely investigated in tumors as the E3 ligase; for example, CBX4 governs HIF-1a to potentiate the angiogenesis of hepatocellular carcinoma (Li et al., 2014). CBX4 has been related to hepatocarcinoma and may represent a novel marker for it (Wang et al., 2013; Li et al., 2014; Jiao et al., 2015). In our study, we identified CBX4 as an E3 ligase of HDAC7 using a series of assays. The ubiquitin level is typically determined by two factors: one factor is the construction change of the substrates, which is typically caused by various processes of decoration such as phosphorylation, and the other is the increase in E3 ligase (Lee et al., 2013; Berlin et al., 2013). HDAC7 is phosphorylated by specific signaling pathways (Dequiedt et al., 2005; Ha et al., 2008); therefore, we investigated whether phosphorylation and/or CBX4 contributed to the change of HDAC7 in CFC. We determined that HDAC7 phosphorylation did not affect its interaction with CBX4 or its ubiquitin level, whereas the E3 ligase CBX4 increased during CFC, which indicated that the increase in CBX4 is the main reason for the degradation of HDAC7 in CFC. Nevertheless, the findings indicated that $\mathrm{CBX} 4$ is not completely responsible for HDAC7 degradation in the ubiquitin pathway (Figs. $4 \mathrm{H}, 5 \mathrm{C}$ ), which indicates that there may be other E3 ligases necessary.

\section{Nur77 involved in the formation of CFC as one of the target genes of HDAC7}

As discussed previously, different HDACs are involved in different memory procedures, which may be a result of the different target genes regulated by HDACs (Guan et al., 2002; Fischer et al., 2010). In this case, we investigated the target genes of HDAC7. We found that Nur77 increased quickly after CFC training and was back to baseline $\sim 4 \mathrm{~h}$ later, which IS consistent with the previous reports (von Hertzen and Giese, 2005; Vecsey et al., 2007; Radwanska et al., 2011; Hawk et al., 2012). However, the second increase of Nur77 at 6-24 h after CFC training is different from the previous study (Hawk et al., 2012). The reason for this difference may be attributed to the detected areas of hippocampus. Our study measured the expression of Nur77 in the DH and the $\mathrm{VH}$, whereas previous studies chose the whole hippocampus as the target region. It is possible that no changes of Nur77 in the VH during CFC formation cover up the increase of Nur77 in the $\mathrm{DH}$ when they are mixed together. Some reports have indicated that HDAC7 was recruited to the upstream of Nur77 transcriptional start site, which repressed the Nur77 transcription under basal conditions (Dequiedt et al., 2003, 2005; Kasler and Verdin, 2007; Chen et al., 2009). The repressive roles of HDAC7 could be controlled by the nucleocytoplasmic shuttling, which was triggered by HDAC7 phosphorylation (McKinsey et al., 2000, 2001;
Dequiedt et al., 2005; Ha et al., 2008). We speculated that the increased Nur77 expression $1 \mathrm{~h}$ after CFC was related to the exported HDAC7 caused by its phosphorylation, which enhanced significantly in the $\mathrm{DH}$ at the same time. Previous reports indicated that BDNF was released soon after CFC training (Chen et al., 2007; Takei et al., 2011). When BDNF was used to stimulate the hippocampus neurons, we found the HDAC7 localized primarily in the nucleus of neurons exported to the cytoplasm $1 \mathrm{~h}$ after BDNF treatment (data not shown). This result suggests that HDAC7 localization may change after CFC training. Six hours after conditioning, the protein levels of HDAC7 decreased significantly, which effectively increased the H4K12 acetylation and removed the inhibition on Nur77 transcription and may have been the reason for the Nur77 increase. Moreover, both the results that Nur77 protein level changed along with the HDAC7 and that the effects of sh-Nur77 on LTM could not be rescued by sh-HDAC7 indicated that Nur77 is involved in the formation of CFC as one of the target genes of HDAC7.

In conclusion, the current findings demonstrated the effect and the potential mechanisms of HDAC7 on hippocampaldependent memories. All of these proteins, including HDAC7, CBX4, and Nur77, could be potential therapeutic targets for preventing memory deficits in aging and neurological diseases.

\section{References}

Bahari-Javan S, Maddalena A, Kerimoglu C, Wittnam J, Held T, Bähr M, Burkhardt S, Delalle I, Kügler S, Fischer A, Sananbenesi F (2012) HDAC1 regulates fear extinction in mice. J Neurosci 32:5062-5073. CrossRef Medline

Berlin K, Castañeda CA, Schneidman-Duhovny D, Sali A, Nava-Tudela A, Fushman D (2013) Recovering a representative conformational ensemble from underdetermined macromolecular structural data. J Am Chem Soc 135:16595-16609. CrossRef Medline

Broide RS, Redwine JM, Aftahi N, Young W, Bloom FE, Winrow CJ (2007) Distribution of histone deacetylases 1-11 in the rat brain. J Mol Neurosci 31:47-58. CrossRef Medline

Canettieri G et al. (2010) Histone deacetylase and Cullin3-RENKCTD11 ubiquitin ligase interplay regulates Hedgehog signalling through Gli acetylation. Nat Cell Biol 12:132-142. CrossRef Medline

Chang S, Young BD, Li S, Qi X, Richardson JA, Olson EN (2006) Histone deacetylase 7 maintains vascular integrity by repressing matrix metalloproteinase 10. Cell 126:321-334. CrossRef Medline

Chen J, Kitanishi T, Ikeda T, Matsuki N, Yamada MK (2007) Contextual learning induces an increase in the number of hippocampal CA1 neurons expressing high levels of BDNF次. Neurobiol Learn Mem 88:409-415. CrossRef Medline

Chen J, Fiskus W, Eaton K, Fernandez P, Wang Y, Rao R, Lee P, Joshi R, Yang Y, Kolhe R, Balusu R, Chappa P, Natarajan K, Jillella A, Atadja P, Bhalla KN (2009) Cotreatment with BCL-2 antagonist sensitizes cutaneous T-cell lymphoma to lethal action of HDAC7-Nur77-based mechanism. Blood 113:4038-4048. CrossRef Medline

Dequiedt F, Kasler H, Fischle W, Kiermer V, Weinstein M, Herndier BG, Verdin E (2003) HDAC7, a thymus-specific class II histone deacetylase, regulates Nur77 transcription and TCR-mediated apoptosis. Immunity 18:687-698. CrossRef Medline

Dequiedt F, Van Lint J, Lecomte E, Van Duppen V, Seufferlein T, Vandenheede JR, Wattiez R, Kettmann R (2005) Phosphorylation of histone deacetylase 7 by protein kinase D mediates T cell receptor-induced Nur77 expression and apoptosis. J Exp Med 201:793-804. CrossRef Medline

Fischer A, Sananbenesi F, Mungenast A, Tsai LH (2010) Targeting the correct $\mathrm{HDAC}(\mathrm{s})$ to treat cognitive disorders. Trends Pharmacol Sci 31:605617. CrossRef Medline

Fortress AM, Fan L, Orr PT, Zhao Z, Frick KM (2013) Estradiol-induced object recognition memory consolidation is dependent on activation of mTOR signaling in the dorsal hippocampus. Learn Mem 20:147-155. CrossRef Medline

Govindarajan N, Rao P, Burkhardt S, Sananbenesi F, Schlüter OM, Bradke F, Lu J, Fischer A (2013) Reducing HDAC6 ameliorates cognitive deficits 
in a mouse model for Alzheimer's disease. EMBO Mol Med 5:52-63. CrossRef Medline

Gräff J, Joseph NF, Horn ME, Samiei A, Meng J, Seo J, Rei D, Bero AW, Phan TX, Wagner F, Holson E, Xu J, Sun J, Neve RL, Mach RH, Haggarty SJ, Tsai LH (2014) Epigenetic priming of memory updating during reconsolidation to attenuate remote fear memories. Cell 156:261-276. CrossRef Medline

Guan JS, Haggarty SJ, Giacometti E, Dannenberg JH, Joseph N, Gao J, Nieland TJ, Zhou Y, Wang X, Mazitschek R, Bradner JE, DePinho RA, Jaenisch R, Tsai LH (2009) HDAC2 negatively regulates memory formation and synaptic plasticity. Nature 459:55-60. CrossRef Medline

Guan Z, Giustetto M, Lomvardas S, Kim JH, Miniaci MC, Schwartz JH, Thanos D, Kandel ER (2002) Integration of long-term-memory-related synaptic plasticity involves bidirectional regulation of gene expression and chromatin structure. Cell 111:483-493. CrossRef Medline

Guise AJ, Mathias RA, Rowland EA, Yu F, Cristea IM (2014) Probing phosphorylation-dependent protein interactions within functional domains of histone deacetylase 5 (HDAC5). Proteomics 14:2156-2166. CrossRef Medline

Gupta-Agarwal S, Franklin AV, Deramus T, Wheelock M, Davis RL, McMahon LL, Lubin FD (2012) G9a/GLP histone lysine dimethyltransferase complex activity in the hippocampus and the entorhinal cortex is required for gene activation and silencing during memory consolidation. J Neurosci 32:5440-5453. CrossRef Medline

Ha CH, Jhun BS, Kao HY, Jin ZG (2008) VEGF stimulates HDAC7 phosphorylation and cytoplasmic accumulation modulating matrix metalloproteinase expression and angiogenesis. Arterioscler Thromb Vasc Biol 28:1782-1788. CrossRef Medline

Hawk JD, Florian C, Abel T (2011) Post-training intrahippocampal inhibition of class I histone deacetylases enhances long-term object-location memory. Learn Mem 18:367-370. CrossRef Medline

Hawk JD, Bookout AL, Poplawski SG, Bridi M, Rao AJ, Sulewski ME, Kroener BT, Manglesdorf DJ, Abel T (2012) NR4A nuclear receptors support memory enhancement by histone deacetylase inhibitors. J Clin Invest 122:3593-3602. CrossRef Medline

Huff NC, Rudy JW (2004) The amygdala modulates hippocampus-dependent context memory formation and stores cue-shock associations. Behav Neurosci 118:53-62. CrossRef Medline

Huff NC, Frank M, Wright-Hardesty K, Sprunger D, Matus-Amat P, Higgins E, Rudy JW (2006) Amygdala regulation of immediate-early gene expression in the hippocampus induced by contextual fear conditioning. J Neurosci 26:1616-1623. CrossRef Medline

Jagirdar R, Drexel M, Bukovac A, Tasan RO, Sperk G (2016) Expression of class II histone deacetylases in two mouse models of temporal lobe epilepsy. J Neurochem 136:717-730. CrossRef Medline

Jiao HK, Xu Y, Li J, Wang W, Mei Z, Long XD, Chen GQ (2015) Prognostic significance of $\mathrm{Cbx} 4$ expression and its beneficial effect for transarterial chemoembolization in hepatocellular carcinoma. Cell Death Dis 6:e1689. CrossRef Medline

Kandel ER, Dudai Y, Mayford MR (2014) The molecular and systems biology of memory. Cell 157:163-186. CrossRef Medline

Kasler HG, Verdin E (2007) Histone deacetylase 7 functions as a key regulator of genes involved in both positive and negative selection of thymocytes. Mol Cell Biol 27:5184-5200. CrossRef Medline

Kim MS, Akhtar MW, Adachi M, Mahgoub M, Bassel-Duby R, Kavalali ET, Olson EN, Monteggia LM (2012) An essential role for histone deacetylase 4 in synaptic plasticity and memory formation. J Neurosci 32:1087910886. CrossRef Medline

Kim M, Ham A, Kim JY, Brown KM, D’Agati VD, Lee HT (2013) The volatile anesthetic isoflurane induces ecto-5'-nucleotidase (CD73) to protect against renal ischemia and reperfusion injury. Kidney Int 84:90-103. CrossRef Medline

KitazawaS, Kameda T, Kumo A, Yagi-Utsumi M, Baxter NJ, Kato K, Williamson MP, Kitahara R (2014) Close identity between alternatively folded state N2of ubiquitin and the conformation of the protein bound to the ubiquitin-activating enzyme. Biochemistry 53:447-449. CrossRef Medline

Lee JW, Heo SW, Lee SJ, Ko JY, Kim H, Kim HI (2013) Probing conformational changes of ubiquitin by host-guest chemistry using electrospray ionization mass spectrometry. J Am Soc Mass Spectrom 24:21-29. CrossRef Medline

Li J, Xu Y, Long XD, Wang W, Jiao HK, Mei Z, Yin QQ, Ma LN, Zhou AW, Wang LS, Yao M, Xia Q, Chen GQ (2014) Cbx4 governs HIF-1 $\alpha$ to potentiate angiogenesis of hepatocellular carcinoma by its SUMO E3 ligase activity. Cancer Cell 25:118-131. CrossRef Medline

Li X, Song S, Liu Y, Ko SH, Kao HY (2004) Phosphorylation of the histone deacetylase 7 modulates its stability and association with $14-3-3$ proteins. J Biol Chem 279:34201-34208. CrossRef Medline

Li Z, Hao Q, Luo J, Xiong J, Zhang S, Wang T, Bai L, Wang W, Chen M, Wang W, Gu L, Lv K, Chen J (2016) USP4 inhibits p53 and NF- $\kappa$ B through deubiquitinating and stabilizing HDAC2. Oncogene 35:2902-2912. CrossRef Medline

Lopez-Fernandez MA, Montaron MF, Varea E, Rougon G, Venero C, Abrous DN, Sandi C (2007) Upregulation of polysialylated neural cell adhesion molecule in the dorsal hippocampus after contextual fear conditioning is involved in long-term memory formation. J Neurosci 27:4552-4561. CrossRef Medline

Luczynski P, Whelan SO, O'Sullivan C, Clarke G, Shanahan F, Dinan TG, Cryan JF (2016) Adult microbiota-deficient mice have distinct dendritic morphological changes: differential effects in the amygdala and hippocampus. Eur J Neurosci 44:2654-2666. CrossRef Medline

Margariti A, Zampetaki A, Xiao Q, Zhou B, Karamariti E, Martin D, Yin X, Mayr M, Li H, Zhang Z, De Falco E, Hu Y, Cockerill G, Xu Q, Zeng L (2010) Histone deacetylase 7 controls endothelial cell growth through modulation of beta-catenin. Circ Res 106:1202-1211. CrossRef Medline

McGaugh JL (2004) The amygdala modulates the consolidation of memories of emotionally arousing experiences. Annu Rev Neurosci 27:1-28. CrossRef Medline

McKinsey TA, Zhang CL, Olson EN (2000) Activation of the myocyte enhancer factor-2 transcription factor by calcium/calmodulin-dependent protein kinase-stimulated binding of 14-3-3 to histone deacetylase 5 . Proc Natl Acad Sci U S A 97:14400-14405. CrossRef Medline

McKinsey TA, Zhang CL, Olson EN (2001) Identification of a signalresponsive nuclear export sequence in class II histone deacetylases. Mol Cell Biol 21:6312-6321. CrossRef Medline

McQuown SC, Barrett RM, Matheos DP, Post RJ, Rogge GA, Alenghat T, Mullican SE, Jones S, Rusche JR, Lazar MA, Wood MA (2011) HDAC3 is a critical negative regulator of long-term memory formation. J Neurosci 31:764-774. CrossRef Medline

Mottet D, Bellahcène A, Pirotte S, Waltregny D, Deroanne C, Lamour V, Lidereau R, Castronovo V (2007) Histone deacetylase 7 silencing alters endothelial cell migration, a key step in angiogenesis. Circ Res 101:12371246. CrossRef Medline

Narlikar GJ, Fan HY, Kingston RE (2002) Cooperation between complexes that regulate chromatin structure and transcription. Cell 108:475-487. CrossRef Medline

Ogden KK, Khatri A, Traynelis SF, Heldt SA (2014) Potentiation of GluN2C/D NMDA receptor subtypes in the amygdala facilitates the retention of fear and extinction learning in mice. Neuropsychopharmacology 39:625-637. CrossRef Medline

O'Leary OF, O'Connor RM, Cryan JF (2012) Lithium-induced effects on adult hippocampal neurogenesis are topographically segregated along the dorso-ventral axis of stressed mice. Neuropharmacology 62:247-255. CrossRef Medline

Païzanis E, Renoir T, Lelievre V, Saurini F, Melfort M, Gabriel C, Barden N, Mocaër E, Hamon M, Lanfumey L (2010) Behavioural and neuroplastic effects of the new-generation antidepressant agomelatine compared to fluoxetine in glucocorticoid receptor-impaired mice. Int J Neuropsychopharmacol 13:759-774. CrossRef Medline

Papatheodoropoulos C (2015) Higher intrinsic network excitability in ventral compared with the dorsal hippocampus is controlled less effectively by GABAB receptors. BMC Neurosci 16:75. CrossRef Medline

Parra M, Mahmoudi T, Verdin E (2007) Myosin phosphatase dephosphorylates HDAC7, controls its nucleocytoplasmic shuttling, and inhibits apoptosis in thymocytes. Genes Dev 21:638-643. CrossRef Medline

Penney J, Tsai LH (2014) Histone deacetylases in memory and cognition. Sci Signal 7:re12. CrossRef Medline

Radwanska K, Medvedev NI, Pereira GS, Engmann O, Thiede N, Moraes MF, Villers A, Irvine EE, Maunganidze NS, Pyza EM, Ris L, Szymańska M, Lipiński M, Kaczmarek L, Stewart MG, Giese KP (2011) Mechanism for long-term memory formation when synaptic strengthening is impaired. Proc Natl Acad Sci U S A 108:18471-18475. CrossRef Medline

Rudy JW, Barrientos RM, O'Reilly RC (2002) Hippocampal formation supports conditioning to memory of a context. Behav Neurosci 116:530-538. CrossRef Medline 
Shi W, Wei X, Wang Z, Han H, Fu Y, Liu J, Zhang Y, Guo J, Dong C, Zhou D, Zhou Q, Chen Y, Yi F (2016) HDAC9 exacerbates endothelial injury in cerebral ischaemia/reperfusion injury. J Cell Mol Med. 2016;20:11391149. CrossRef Medline

Szyf M (2014) Epigenetics, a key for unlocking complex CNS disorders? Therapeutic implications. Eur Neuropsychopharmacol 2015;25:682-702. CrossRef Medline

Takei S, Morinobu S, Yamamoto S, Fuchikami M, Matsumoto T, Yamawaki S (2011) Enhanced hippocampal BDNF/TrkB signaling in response to fear conditioning in an animal model of posttraumatic stress disorder. J Psychiatr Res 45:460-468. CrossRef Medline

Vecsey CG, Hawk JD, Lattal KM, Stein JM, Fabian SA, Attner MA, Cabrera SM, McDonough CB, Brindle PK, Abel T, Wood MA (2007) Histone deacetylase inhibitors enhance memory and synaptic plasticity via CREB: CBP-dependent transcriptional activation. J Neurosci 27:6128-6140. CrossRef Medline

Vieira PA, Korzus E (2015) CBP-Dependent memory consolidation in the prefrontal cortex supports object-location learning. Hippocampus 25: 1532-1540. CrossRef Medline

von Hertzen LS, Giese KP (2005) Memory reconsolidation engages only a subset of immediate-early genes induced during consolidation. J Neurosci 25:1935-1942. CrossRef Medline

Wang B, Tang J, Liao D, Wang G, Zhang M, Sang Y, Cao J, Wu Y, Zhang R, Li S, Ding W, Zhang G, Kang T (2013) Chromobox Homolog 4 Is correlated with prognosis and tumor cell growth in hepatocellular carcinoma. Ann Surg Oncol 20:684-692. CrossRef Medline

Woldemichael BT, Bohacek J, Gapp K, Mansuy IM (2014) Epigenetics of memory and plasticity. Prog Mol Biol Transl Sci 2014;122:305-340. CrossRef Medline

Xu N, Zhou WJ, Wang Y, Huang SH, Li X, Chen ZY (2015) Hippocampal Wnt $3 a$ is necessary and sufficient for contextual fear memory acquisition and consolidation. Cereb Cortex 25:4062-4075. CrossRef Medline

Yu H, Wang DD, Wang Y, Liu T, Lee FS, Chen ZY (2012) Variant brainderived neurotrophic factor Val66Met polymorphism alters vulnerability to stress and response to antidepressants. J Neurosci 32:4092-4101. CrossRef Medline

Zhao Z, Fan L, Frick KM (2010) Epigenetic alterations regulate estradiolinduced enhancement of memory consolidation. Proc Natl Acad Sci U S A 107:5605-5610. CrossRef Medline 